\title{
AN ANALYSIS OF THE RELATIONSHIP BETWEEN OBSESSIVE- COMPULSIVE PERSONALITY, RUNNING ADDICTION AND RUNNING COMMITMENT IN ELITE RUNNERS
}
Richard Murrell Ferguson, Jr. Appomattox, Virginia

B.S., James Madison University, 1980 M.Ed., University of Virginia, 1984
A Dissertation Presented to the Graduate Faculty of the University of Virginia in Candidacy for the Degree of Doctor of Philosophy

\author{
Department of Education \\ University of Virginia \\ May 1991
}


Department of Human Services

Curry School of Education

University of Virginia

Charlottesville, Virginia

APPROVAL OF THE DISSERTATION

This dissertation, An Analysis of the Relationship Between Obsessive-Compulsive Personality, Running Addiction and Running Commitment, has been approved by the Graduate Faculty of the Curry school of Education in partial fulfillment of the requirements for the degree of Doctor of Philosophy (Education).

Robot Ratel

Dr. Robert Rotella, Advisor

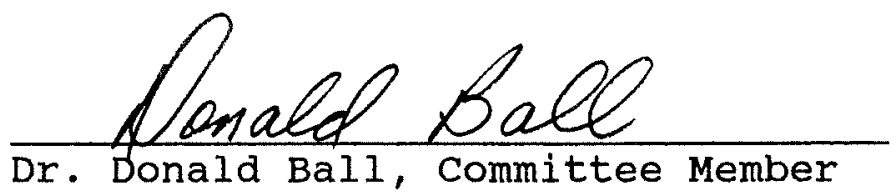

Linda Bunker

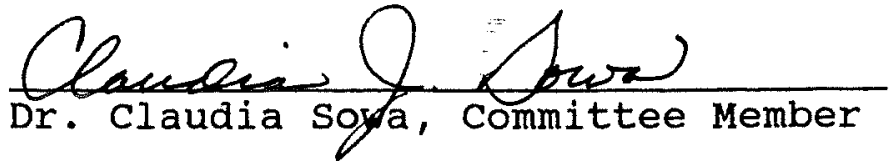

april 23,1991_ Date 


\section{ABSTRACT}

This research examined the relationship between running addiction, running commitment and obsessive-compulsive personality as measured by the Negative Addiction Scale (Hailey \& Bailey, 1982), Commitment to Running scale (Carmack \& Martens, 1979), and the Obsessive-Compulsive Scale (Gibb, Bailey, Best \& Lambirth, 1983) respectively. Demographic data on sex and age of subjects was also gathered.

Elite distance runners $(N=143)$ served as subjects in the research. Subjects were also broken into categories by sex (male=95, female=48) and by age (open=115, masters=28) . Subjects were mailed the Running Behavior Questionnaire which was made up of the Negative Addiction Scale, Commitment to Running scale and the Obsessive-Compulsive Scale. A response rate of $72 \%$ was obtained for the sample. Multiple regression analysis revealed running addiction and running commitment are not significant predictors of obsessive-compulsive personality when the sample was considered as a whole or was split by sex and age groupings.

Factor analysis revealed seventeen factors with eigen values of one or greater when all items from the three instruments employed were placed into a principle component analysis with varimax rotation. None of the seventeen factors could be labeled, when three factors were specified items from the Commitment to Running scale significantly loaded on one factor while items contained in the obsessive- 
Compulsive Scale loaded significantly on another. Items from the Negative Addiction Scale failed to load.

Results did not support the theory that one underlying construct was in operation between running addiction, running commitment and obsessive-compulsive personality based upon the lack of significant results from multiple regression analysis and the failure of one clear factor to be extracted in factor analysis. However, the reliability and validity of the Negative Addiction Scale was questioned. Recommendations for future research included the development of sport-specific measuring instruments for obsessivecompulsive personality, the use of qualitative research methods, the examination of childhood and adolescent experiences to determine how dysfunctional exercise behavior develops and the further examination of motivations for running. 


\section{DEDICATION}

To my wife Jill. . .whose never ending love, friendship, encouragement, understanding and above all infinite faith in me provided the environment for the completion of my education.

Through the ups, downs and in-betweens, Jill was there. Without her this project could never have been completed. I look forward to sharing everyday of the rest of my life with her. We both believe in chasing our dreams and together we see nothing is impossible. 


\section{ACKNOWLEDGEMENTS}

To complete a project such as this requires the help of many dedicated friends and professionals. I would like to express my sincere appreciation to each of the following people:

To my wife, Jill, for her love and support during a very trying period in my life.

To my mother and father, Easley and Murrell Ferguson, for their support and instilling in me the value of not giving up and the importance of reaching for goals.

To Becky Burbach for being able to read my handwriting and typing this manuscript.

To Kit Pollack and Dr. Bruce Gansneder for their skilled assistance with computer work and interpretation.

To every individual who encouraged me to keep going and not "give in" and made me shed a smile through some difficult times.

A very, very special thank you and acknowledgement of appreciation goes to my doctoral committee for their patience, encouragement, support, understanding and true professionalism. I offer a sincere thanks to the following people:

Dr. Linda Bunker for her constant belief in my academic abilities and her high standards of excellence which she instilled in me. Above all Dr. Bunker encouraged and 
supported me during the most critical times when my confidence was at its lowest. With her guidance and expert advice I pressed on and regained my perspective and goals; Dr. Claudia Sowa for her never ending encouragement and support. Dr. Sowa was always there to talk to and to listen;

Dr. Donald Ball for his expert advice in the statistical and computer areas, for his encouragement and for his ability to reassure me and helping me keep the whole project in perspective; and

Dr. Robert Rotella for believing in me, for never giving up on me, for listening to my ideas, and for being an individual who I could turn to for advice. Above all I must thank Dr. Rotella for giving me the opportunity to reach a major goal and to learn many new and exciting things. 
TABLE OF CONTENTS

Page

Dedication.............................

Acknowledgements......................... iii

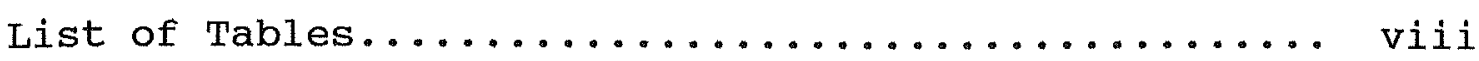

List of Figures......................... ix

CHAPTER

I INTRODUCTION......................... 1

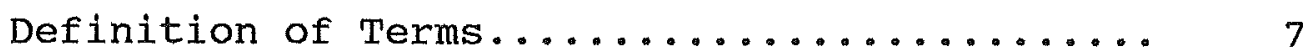

statement of the Problem............... 11

Need for the study...................... 11

Research Questions...................... 12

II $\quad$ REVIEW OF ITTERATURE................... 13

Introduction........................ 13

Historical Review....................... 14

Obsessions and Compulsions............... 16

Comparisons with other Disorders........... 32

Obsessive-Compulsive and Depression......... 34

Perfectionism and Obsessive-Compulsive symptomology....................... 36

Narcissism, Perfection and the ObsessiveCompulsive........................ 40

Workaholism and Obsessive-Compulsive........ 41

Personality Factors in Obsessive-Compulsive

Disorders......................... 


\section{TABLE OF CONTENTS (continued)}

CHAPTER

Page

Obsessive-Compulsive Addiction and Running commitment.

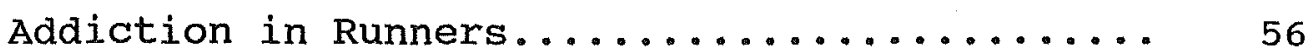

When Runners Can't Run................. 58

Measurement of Obsessive-Compulsive

Personality and Running Addiction......... 65

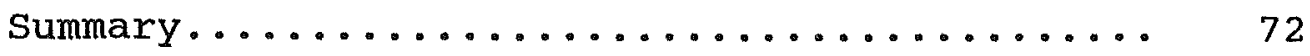

III METHODOLOGY.............................. 73

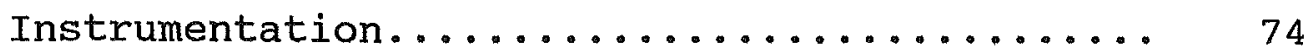

Obsessive-Compulsive Personality............ 74

Running Commitment................... 77

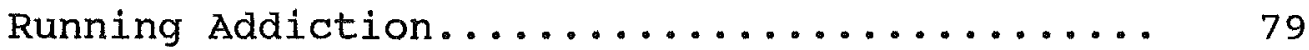

Demographic Data..................... 81

Selection of subjects................... 81

Instructions to subjects................ 82

Human subjects clearance................. 85

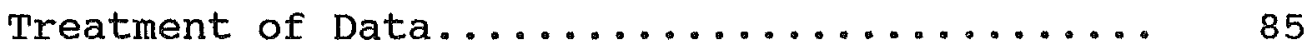

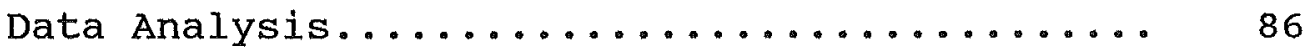

Research Questions..................... 88

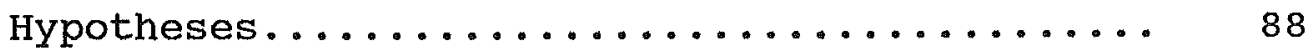

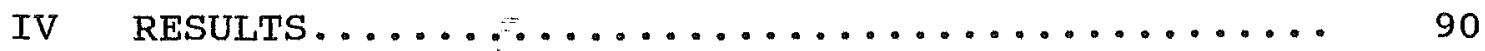

Demographic and Descriptive Data.......... 91

The Predictive Influence of Running Addiction and Running commitment on ObsessiveCompulsive Personality................ 


\section{TABLE OF CONTENTS (continued)}

CHAPTER

Page

Multiple Regression Employing Al1 Subjects.. 94

Multiple Regression: Male-Female Split..... 96

Multiple Regression: Open-Masters Split.... 103

Principle Factors in the Negative (Running)

Addiction Commitment to Running, and

Obsessive-Compulsive Personality Scales..... 106

Reliablity of the Scales................. 114

Summary and Conclusions.................. 115

Results of the Test of Null Hypotheses....... 117

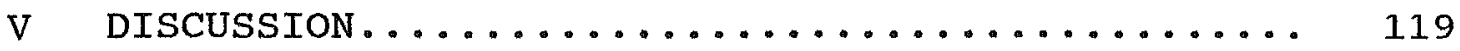

Discussion of Major Findings............. 120

Conclusions........................... 144

Limitations........................ 146

Recommendations for Future Research......... 147

REFERENCES............................... 150

APPENDICES

Appendix A: Obsessive-Compulsive Scale.......... 159

Appendix B: Negative Addiction Scale............. 161

Appendix c: Commitment to Running Scale.......... 164

Appendix D: Running Behavior Questionnaire........ 166

Appendix $\mathrm{E}:$ Cover Letter...................... 174

Appendix F: Followup Notice................. 178 
1 Means, Standard Deviations and Ranges for Scores on the Negative (Running) Addiction Scale, Running commitment scale and the Obsessive-Compulsive Personality Scale........

2 Intercorrelations Between Negative (Running) Addiction, Running Commitment and obsessive-

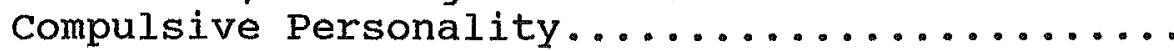

Multiple Regression of Negative (Running) Addiction and Running Commitment on obsessiveCompulsive Personality..................

Intercorrelations Between Negative (Running) Addiction, Running commitment and obsessiveCompulsive Personality in Females............

Multiple Regression of Negative (Running) Addiction and Running commitment on obsessiveCompulsive Personality in Females...........

Intercorrelations Between Negative (Running) Addiction, Running Commitment and obsessiveCompulsive Personality in Males.............

7 Multiple Regression of Negative (Running) Addiction and Running Commitment on obsessiveCompulsive Personality in Males.............

8 Intercorrelations Between Negative (Running) Addiction, Running Commitment and obsessiveCompulsive Personality in Open Runners........ 104

9 Multiple Regression of Negative (Running) Addiction and Running Commitment on obsessiveCompulsive Personality in Open Runners........ 105

10 Intercorrelations Between Negative (Running) Addiction, Running Commitment and ObsessiveCompulsive Personality in Masters Runners..... 107

11 Multiple Regression of Negative (Running) Addiction and Running Commitment on obsessiveCompulsive Personality in Masters Runners...... 


\section{LIST OF TABLES (continued)}

TABLE

Page

12 Orthoginally Rotated Factor Matrix for Negative (Running) Addiction Scale, Commitment to Running Scale and obsessiveCompulsive Personality Scale Items........... 110

13 Reliablity Measures of the Negative (Running) Addiction Scale, Commitment to Running Scale and the Obsessive-Compulsive Scale......... 116 


\section{LIST OF FIGURES}

\section{FIGURE}

Page

1 Obsessional thoughts and preoccupations:

The similarities and differences............ 22

2 Typology of Workaholism.................. 44

3 Model of Participation in Running............ 60

4 Movement Patterns in the Model of Participation

in Running......................... 63

5 Major Problems Involved in the Assessment of obsessional Illness..................... 69

6 Comparison of Selected Items from the Negative (Running) Addiction Sclae, Commitment to Running Scale and the obsessive-Compulsive

scale.............................. 122 
CHAPTER I

\section{INTRODUCTION}

In recent years the rise in the popularity and visibility of running has led to a proliferation of questions about running. Many individuals have speculated about the psychological makeup of runners and how runners may think. Such analyses have appeared in popular literature and have usually been based upon personal insights of runners or writers. As a result a substantial body of literature has been generated by the running boom, however much of this is largely non-empirical and subjective. Few large sample studies have been conducted to systematically survey the psychological factors involved in running; yet such information is essential if we are to better understand the "mind of the runner".

Since the running boom of the early 1980 s sport psychologists and other psychology professionals have studied runners and the mental processes involved with running and how these processes effect the body and its health, behavior and performance. From observation and research, the psychological community has identified a construct which has been termed running addiction (Sachs, $1981)$ 
Many other terms have been used to describe a consistent pattern of running behavior in individuals. These terms include commitment (Carmack \& Martens, 1979), compulsion (Abel, 1975), dependence (Sachs \& Pargman, 1979), obsession (Waters, 1981), healthy habit (Peele, 1981), addiction (Glasser, 1976; Kostrubala, 1976; Sachs, 1981); and positive addiction (Glasser, 1976). However, these terms do not necessarily equate with each other. They appear to be separate psychological terms which should not have been used interchangeably. It is hoped that the current research effort will better clarify the confusion that exists in the present terminology of running research. "Addiction" has been the term which most researchers and the general public have attached to the extended involvement of some runners in their activity. The concept of addiction in relation to such salubrious experiences as exercise and running was first popularized by william Glasser (1976). Since then, mention of running addiction frequently appears in scholarly journals and popular publications. Yet, research evidence on running addiction is limited because of the relative infancy of the concept and difficulty in measuring the construct.

According to Glasser (1967) running addiction can be defined as psychological and/or physiological dependence on a regular regiment of running, characterized by withdrawal symptoms after twenty-four to thirty-six hours without the 
activity. Glasser (1976) argues that withdrawal symptoms including anxiety, restlessness, guilt, irritability, tension, bloating, and muscle discomfort appear to be critical in determining the existence of addiction. Some runners even report suffering apathy, sluggishness, weightloss, headaches, insomnia and gastric distress.

It can be argued that the symptoms of exercise addiction would indicate some strong physiological or psychological underpinning for the need to run. Morgan (1979) cites a number of case studies in which runners are consumed by the need to run. These runners dramatically alter their daily schedules and neglect the responsibilities of work, home, and family. Morgan (1980) suggested runners in his case study suffered from running addiction. However, it is possible that this is a mislabel. What appears to be a running addiction could in fact be simple commitment or an obsessive-compulsive disorder. It is important to differentiate these in order to determine if the tendency is a positive or negative factor in health and performance and to effectively determine the appropriate treatment response.

Individuals suffering from obsessive-compulsive disorders suffer from obsessions, which are defined as persistent ideas, thoughts, impulses or images that are experienced as senseless (American Psychological Association (APA), 1980). The person wants to control the obsession but can't. A good example would be a flu ridden runner who 
keeps thinking, "I need to run today," even though he knows he is ill and may damage his health.

To reduce the anxiety associated with the obsession the runner usually has some type of compulsion which is an intentional behavior that is performed in response to the obsession. The compulsive behavior is designed to prevent discomfort which occurs if the obsession is not reduced. However, the behavior is not realistically connected with what it is designed to reduce or the behavior is done to extreme excess. Going back to the example of an injured runner, he runs anyway, possibly longer than normal, even though subjectively he knows he should not. The runner knows his behavior is excessive and he doesn't even get pleasure out of it, but he must run to relieve the tension, anxiety and uneasiness which results from having the obsession. As a result, anxiety and tension will build up to an unmanageable level until the person can run. From this viewpoint, anxiety is not a withdrawal symptom, but a result of an obsessional thought pattern about running. The obsession is the desire to run, while the compulsion is the act of running. The key point to remember is obsessions are ideas or thoughts, compulsions are behaviors or cognitive rituals.

Many other phenomena of the psyche have been confused with obsessive-compulsive disorders in the past. often the terms which describe psychological complaints are used 
inappropriately. A good example is obsessive-compulsive personality disorder. People who suffer from obsessivecompulsive personality disorder often strive for perfection, but their own strict and often unattainable standards interfere with the actual attainment of goals. Nothing is ever good enough for these people (Ingram, 1982). The obsessive-compulsive personality is interested in conscientiousness and details. They also show extreme overcompetitiveness (APA, 1980). Horney (1950) argued that the obsessive-compulsive's sole reward for success is the pleasures of triumph over someone else. For them there is nothing without success. Work and productivity are prized at the exclusion of pleasure and interpersonal relationships (Salkovskis, 1985). Pleasure is something that must be worked for (APA, 1980). Certainly this adherence to work and productivity could be confused with what running researchers called "addicted."

Much of the confusion could be eliminated since the DSM-III (APA, 1980) has made it clear that obsessivecompulsive disorders are indeed a distinct set of psychological anomalities. Sometimes they have been confused with phobias because of the anxiety involved. However for a phobic behavior pattern to be evident avoidance behavior must bring relief from anxiety, but in obsessive-compulsive patients there can be no relief of a permanent form because it is impossible to avoid the 
thoughts in their head (Rachman, 1976). Phobias are actually avoided for relief while obsessions are acted upon in order to reduce anxiety.

Sachs (1981) has presented evidence that addicted runners who are forced to layoff often suffer from depression. Depression also occurs frequently in obsessivecompulsive patients in the general population (Insel, 1985). In fact a major depressive episode occurs in at least fifty percent of obsessive-compulsive cases (Gittleson, 1966).

It must be asked here if such runners are suffering any type of psychological illness. It is possible that such individuals are simply more dedicated to their sport and their health than most. As Carmack and Martens (1979) have argued these individuals may simply be more committed than others and suffer no psychological disorders whatsoever.

Another word which often appears in the literature is "perfectionism." In review, perfection has very much in common with obsessive-compulsive complaints, addiction and commitment. Perfectionism has even been listed as one of the diagnostic traits in obsessive-compulsive complaints (APA, 1980). For perfectionists nothing is ever good enough and they demand a higher level of performance than is ever possible to obtain. Perfectionists feel anxious and confused before they ever begin a project (Hamacheck, 1978). The perfectionist is always working and striving, yet very little satisfaction is ever achieved (Beck, 1976). 
Similarly "workaholism" has found its place in some literature. Basically workaholism is an irrational commitment to excessive work (Cherrington, 1980). Schwartz (1982) has suggested that workaholism is a symptom in people of a felt necessity to control themselves and their environment and to avoid emotions. Research (Hathaway, 1984 ) has suggested that some obsessive-compulsive individuals choose work behaviors as compulsions for their obsessional tendencies. It is interesting that workaholism is often considered a virtue in our capitalistic society ingrained with the protestant work ethic. Why then is the runner who exhibits these tendencies labeled as "addicted" or "overtrained"?

other psychological abnormalities such as sex addiction (Wedin, 1984) also present interesting and pertinent comparative findings. Hopefully, through continued research these areas of confusion of obsessive-compulsive complaints, can be clarified.

\section{Definition of Terms}

Several terms in this study are specific to the investigation. The following definitions should help to clarify the issues, objectives, and hypothesis involved in this research.

Addiction occurs when a person's attachment to a sensation, object, or person lessens his appreciation of, 
and ability to deal with other things. He has become dependent on that experience as his only source of gratification (Peele, 1985). Strictly speaking addiction is a state of physiological dependence on a specific substance arising from the habitual use of that substance (Wedin, 1984).

Running addiction is a psychological and/or physiological dependence to a regular regiment of running characterized by withdrawal symptoms after 24 to 36 hours without the activity (Sachs, 1979).

Running commitment is a psychological need which motivates individuals to run. Commitment can be predicted by such factors as length of run, discomfort experienced when a run is missed, and perceived addiction to running.

obsessions are persistent ideas, thoughts, impulses, or images that are experienced as intrusive or senseless, but cannot be stopped (APA, 1980).

Compulsions are repetitive behaviors with a purpose and intention that are performed in response to an obsession, and are governed by certain rules, or in some predetermined fashion (APA, 1980).

Obsessive-Compulsive Disorder has the features of recurrent obsessions or compulsions significantly severe to cause distress or interfere with the individual's normal 
daily routine, job, social functioning, and personal relationships (APA, 1980).

Obsessive-Compulsive Personality Disorder has the essential features of a pervasive pattern of perfectionism and inflexibility. Individuals with this disorder constantly strive for perfection, but this frequently interferes with the actual completion of tasks and projects. They also have preoccupations with rules, trivial details, and procedures. Work and productivity are prized at the exclusion of pleasure and interpersonal relationships (APA, $1980)$.

Perfectionists are those people whose standards are high beyond reach or reason, people who strain compulsively and unremittingly toward impossible goals and who measure their own worth entirely in terms of productivity and accomplishment. These individuals are not involved in the healthy pursuit of excellence (Burns, 1980).

Workaholism is an irrational commitment to excessive work. Workaholics are unable to take time off or divert their energy. They may actually have an obsessivecompulsive personality disorder in that their addictions are symptoms of a felt necessity to control themselves and their environment and to avoid or suppress impulse and affect (Cherrington, 1980). 
Phobia is a persistent fear of a circumscribed stimulus object or situation (other than fear of having a panic attack). Exposure to the stimulus provokes an immediate anxiety response. Anxiety increases or decreases in a fairly predictable manner with changes in the location (nearness) or nature (size) of the phobic stimulus (APA, 1980).

Depressive Episode is either depressed mood or loss of interest or pleasure in all, or almost all, activities and associated activities; for a period of at least two weeks. symptoms present a change from previous functioning. Subject will usually describe feeling depressed, sad, hopeless or discouraged (APA, 1980).

Substance Dependence is impaired control of substance use and the continued use of the substance despite adverse consequences. Symptoms of dependence include, but are not limited to, the physiologic symptoms of tolerance and withdrawal. Symptoms must have persisted for at least one month, or have occurred repeatedly over a longer period of time (APA, 1980). 


\section{Statement of the Problem}

The purpose of this study was to examine the relationship between obsessive-compulsive personality and what the literature has termed "running addiction and commitment." Three objective, paper-pencil type instruments were employed, one measuring running addiction, one running commitment, the other measuring obsessive-compulsive personality. Demographic data was also gathered. The instruments were administered to all members of a United States TAC registered running team with running apparel industrial support $(\mathrm{N}=120)$ and American athletes listed in the Road Race Management Guide to Prize Money Races and Elite Athletes (Stewart, 1990) $(\mathrm{N}=80)$. Survey mail research methods were employed. Scores on the instruments served as dependent measures for the study while performance and involvement perceptions served as the independent measures.

\section{Need for the Study}

Given that research in the area of running psychology is so inconsistent, the need has arisen to study obsessivecompulsive tendencies in runners and to determine if these are the same tendencies which have been labeled running addiction and commitment in the past. With further knowledge in this area sport psychology professionals can better assess the actual complaints of clients and improve 
intervention and treatment. With the improved knowledge of how obsessive-compulsive behavior, running addiction and commitment are interrelated the sport psychologist can better help the runner to higher levels of performance and greater health and personal satisfaction through running.

\section{Research Questions}

The following questions guided the design, implementation and analysis of the study.

1. What is the relationship between obsessivecompulsive personality with running addiction and running commitment? Do measures of running addiction and running commitment accurately share variance with a measure of obsessive-compulsive personality? Is this true for runners in general and when runners are grouped according to sex and age?

2. Is there one underlying factor in operation between running addiction, running commitment and obsessivecompulsive personality? 
CHAPTER II

REVIEW OF LITERATURE

\section{Introduction}

The following review of literature was written to provide a broad-based background for understanding obsessive-compulsive disorders and how these disorders compare and contrast with what has been termed "running addiction" (Sachs, 1981) and running commitment (Carmack \& Martens, 1979).

It would appear from the literature that the terms obsessive-compulsive, addiction, and commitment are used interchangeably, when in fact they are clearly separate entities. This review will attempt to clarify the terms, obsessive-compulsive behavior, running addiction and commitment and determine if they can actually be considered individually in the research literature. Through the comparison and contrast of obsessive-compulsive disorders, commitment and running addiction the framework will be laid to determine the relationship between the three through empirical, scientific research methods. As a result, the sport psychology professional may be better able to assist runners with each tendency in order to improve the quality of their health and performances if such help is deemed necessary. With the proper understanding, running behaviors 
can be better understood in terms of whether the running behaviors are a positive or negative aspect of the runners' health, happiness and performance.

\section{Historical Review}

Recently obsessive compulsive disorders have become the focus of much speculation, research and interest by the general public and clinicians alike. Historically, the disorder has been defined in many different ways. The word obsession, which derives from the Greek obsidere, "to beseige," was originally linked with a form of depression. The French coined the term "folie e doute" after noting that obsessional patients were constantly plagued by uncertainty (Ellenberger, 1970). In his early work with obsessional patients Janet (1970) defined the disorder as a form of psychasthenia. For Freud (1953) obsessional disorder was paired with hysteria as a transference neuroses.

The work that led to today's current conceptions of obsessive-compulsive personality disorders is Freud's (1908) paper, Character and Anal Erotism. Freud observed that the qualities of obstinacy, orderliness and parsimony form a group of traits that are connected with the anal phase of psychosexual development.

Jones (1918) wrote a short paper in which he added the following character traits to those already set forth by Freud: procrastination, sensitivity to interference, marked 
concentration beyond what is called for by the task at hand, boring social qualities, difficulty in having others take responsibility and the inability to enjoy pleasurable situations. Among the anal-erotic character traits he placed incapacity for happiness, irritability and bad temper, hypochondria, miserliness, manners and pettiness, slow mindedness and proneness to bore and a tendency for dictating and tyrannizing (Jones, 1918).

Later Adler (1927) described a cluster of traits, which ultimately would be called obsessive, and later called obsessive-compulsive personality disorder. Adler noted that individuals who possess such traits try to put their lives into formulas and rules (1927). Adler called these individual's desire to rule "boundless." He noted the difficulty these persons show in being creative or using initiative.

The actual title, compulsive character, was first formulated by Wilhem Reich (1949). He pointed out that compulsive character traits are only partly derivative of toilet training difficulty which results in anal eroticism. Pedantry, collecting things, circumstantiality, a tendency to ruminate, and thriftiness are reaction formations to the pleasure associated with producing feces, according to Reich (1949). To the extent that the reaction formations have been unsuccessful, the opposite traits, like sloppiness, 
emerge. Following Reich's train of thought, Erikson (1963) further placed doubt on the importance of toilet training in generating the primordial environment of the compulsive personality. Erikson felt the child learns to isolate his thoughts from his emotions and to repress their resentment over unmet dependency needs and develops counterdependent and obsessive defenses. All feelings become bounded by strict moral attitudes of what is right and wrong.

The early researchers/scholars who studied obsessivecompulsive behaviors laid the foundation for what is being studied today. Many researchers in the past have been more interested in personality traits than in symptomatology, and possibly, a general feeling that the outlook for obsessional disorders is poor has deferred many people from research in this field (Hoogduin, 1986). However, this is rapidly changing. With the Diagnostic and Statistic Manual-III for the American Psychological Association (1980) recognizing Obsessïve-Compulsive Disorder and Obsessive-Compulsive Personality Disorder there has been a sharp new interest kindled in the field.

Obsessions and Compulsions: The Phenomena

The key component of obsessive-compulsive disorders are recurrent obsessions and/or compulsions which are enough to cause severe distress, be time consuming to an abnormal degree, or significantly interfere with the subject's job, 
daily life, social functioning, or interpersonal relationships (APA, 1980).

First of all, terminology needs to be clarified to understand obsessive-compulsive behavior in a forthright, unbiased manner. What really is an obsession? According to the American Psychological Association, obsessions have been defined as persistent ideas, thoughts, impulses, or images that are experienced as intrusive or senseless--such as a person having to check a light switch even though they have checked many times and it was off each time (APA, 1986). The person attempts to ignore or suppress such thoughts or impulses or to neutralize them with some other thought or action. The person recognizes that the obsession is simply a product of their own mind, and is not imposed from without as in some types of delusions (APA, 1980).

Compulsions are repetitive behaviors, with a purpose and intention that are performed in response to an obsession, governed by certain rules or in some predetermined fashion (APA, 1980). The compulsive behavior is designed to reduce or to prevent discomfort or some dreaded situation or occurrence. However, the behavior is not connected in a realistic manner with what it is designed to reduce or the behavior is done in a clearly excessive manner. The act is performed with subjective compulsion that is linked with an initial desire to resist the 
compulsion. The person realizes that their behavior is excessive or unreasonable and does not derive pleasure from performing the activity, although it does provide a release of the tension and anxiety associated with the obsession $(\mathrm{APA}, 1980)$

A good example may be an injured runner. Even though he may realize he is hurt, he continues to think about the need to run. The runner becomes more and more anxious over not being able to run and develop obsessive thought patterns concerning running. He knows he shouldn't run but if he doesn't run he becomes extremely anxious. Therefore, to relieve the anxiety the runner runs anyway risking future injury. He exhibits compulsive running behavior in order to relieve the obsessive anxiety.

When an individual attempts to resist the compulsion, there is a mounting sense of tension that is immediately relieved by giving in to the compulsion. For the runner tension builds up to a degree where the runner must run or they can't function in day to day activities until their run is completed for that day.

Hoogduin (1986) has reported that patients can have obsessional thoughts which were not triggered by any type of activity rather they would occur "out of the blue." An example would be a young women's obsessional thought of going bald which would occur not only when she saw a comb, 
or loose hair but even when no outside stimulus was present she would check her hair to be sure that it remained firmly attached to her scalp. Certainly it is clear that compulsive action cannot always be separated from obsessional thoughts. Dowson (1977) found that various compulsive actions were often related to at least one obsessional thought. However obsessional thoughts are not always accompanied by compulsive actions which Dowson found in two of 41 subjects. Therefore, compulsive actions are viewed as an overt manifestation of some preceding mental activity.

In the past, behavioral and cognitive rituals have been largely misinterpreted. Many people saw these rituals as obsessions. However, rituals actually counteract the sudden obsessional thought and bring relief from tension and anxiety. It was originally Rachman (1976) who compared cognitive rituals and compulsive actions. Foa and steketee (1979) have further suggested that all thoughts, images, and actions that gave rise to anxiety be called "obsessions" and that behavior, thoughts and images that reduce anxiety be called "compulsions." Thoughts which give rise to anxiety are usually very sudden and are followed by feelings of panic. The subjects tend to come to recognize the thought and anticipate when it may trouble them (Hoogduin, 1986). As a result subjects even experience severe anticipatory 
anxiety and avoid particular tasks, events, or situations. Anxiety and tension occur in connection with the thought. Finally with the help of some ritual the subject quells the anxiety and achieves control.

Most people in today's society have some type of obsessional thoughts. Rachman and DeSilva (1978) studied the occurrence of obsessional thoughts in 124 "normal" people and compared these findings with data collected on 8 obsessive-compulsive patients. The researchers found the form, and to a certain extent, the content, the relationship to mood and the consequence for the person concerned were all comparable. However, the obsessional thoughts were not as readily accepted by patients suffering from obsessivecompulsive disorder. The thoughts were more intensely experienced than by the normal group. They provoked more tension and were more frequent. An important finding was the fact that obsessive-compulsive patients resisted the thoughts more and experienced them as more ego-dystonic. Ego-dystonic thoughts are those thoughts which conflict in some way with the personality, norms and previous history (See Figure 1). On the other hand, preoccupations have their content connected with real problems and/or experiences which cause distress. These types of preoccupations cover many areas, such as money worries, and problems connected with home, school or work. The thoughts 
are almost always consistent with the individual's personality and previous history. In contrast Rachman (1973) has pointed out that obsessional thoughts clash with previous experiences and personality and are experienced as dystonic. Preoccupations have a very real, rational basis and patients do not attempt to suppress them as they would obsessional thoughts (Hoogduin, 1986).

Insert Figure 1 near here

Rachman and DeSilva (1978) also reported that obsessive-compulsive patients were more inclined to neutralize the thoughts and often had several obsessional thoughts which were dealt with in the form of some compulsive action. In both groups neutralizing actions served to reduce tensions.

In many cases obsessive-compulsive disorder is confused with obsessive-compulsive personality disorder. Both of the disorders are marked by preoccupation with aggression and control; both utilize the defenses of reaction formation, undoing intellectualization, denial, and isolation of affect (Insel, 1985). From a psychoanalytic perspective it could be suggested that obsessive-compulsive disorder develops when defenses fail to contain the subjects anxiety (Pollack, 1979). This would tend to suggest that Obsessive-Compulsive 


\begin{tabular}{|c|c|c|}
\hline Obsessional thoughts & Preoccupations & \\
\hline \multicolumn{2}{|c|}{$\begin{array}{l}\text { - depressing } \\
\text { - concentration disturbing } \\
\text { - provoking guilt feelings } \\
\text { - experienced as being invasive } \\
\text { - repetitive }\end{array}$} & Siailarities \\
\hline $\begin{array}{l}\text { ego-dyetonle } \\
\text { irrational } \\
\text { provoke resistance } \\
\text { content: } \\
\text { agressive } \\
\text { horrific } \\
\text { often inconceivable } \\
\text { events }\end{array}$ & $\begin{array}{l}\text { ogo-syntonle } \\
\text { rational } \\
\text { no resistance } \\
\text { content: } \\
\text { current } \\
\text { realistic } \\
\text { threatening }\end{array}$ & Differences \\
\hline
\end{tabular}

Figure 1. Obsessional thoughts and preoccupations: The similarities and differences

From "Some similarities and differences between obsessional ruminations and morbid preoccupations" by $S$. Rachman in Canadian Psychiatric Association Journal (1973) 18: 71-74. 
Disorder is on some type of continuum with obsessivecompulsive personality. Evidence however suggest that compulsive personality pathology is neither necessary nor sufficient for the development of obsessive-compulsive disorder (Insel, 1985).

The DSM-III (1980) cites Obsessive-Compulsive Disorder as being a totally separate disorder from obsessive -Compulsive Personality Disorder. Obsessive-Compulsive Disorder, which is sometimes referred to as ObsessiveCompulsive Neurosis, has the key feature of recurrent obsessions or compulsions which are sufficiently severe to cause distress, be time consuming or significantly interfere with the subject's normal routine, occupation, or social activities and relationships with others (APA, 1980).

To review, compulsions are repetitive, purposeful, and intentional behaviors that are performed in response to an obsession, according to certain rules, or in a stereotyped fashion. The behavior is designed to reduce or to prevent discomfort or some dreaded event or situation. The activity, however, is not connected in a realistic way with what it is designed to neutralize or prevent, or it is clearly excessive. The act is done with a sense of subjective compulsion that is linked with a desire to resist the compulsion. The subject actually recognizes that their behavior is excessive and unreasonable. Probably the key 
point is the fact that the subject does not derive any pleasure from carrying out the activity, although it provides a release of tension (APA, 1980).

When a subject attempts to resist a compulsion there is mounting tension that can be immediately relieved by giving into the compulsion. Certainly when a runner is not feeling well and knows they shouldn't run, but becomes anxious and runs anyway, even though they don't enjoy their run, it is something more psychologically deep seeded than dedication to their sport. The runner exercises just to reduce anxiety with health and performance being secondary. The most common compulsions according to Hoogduin (1986) involve hand washing, counting, checking and touching, and fear of contamination. Hoogduin provided the following vignette:

A female patient, suffering from the fear of being contaminated by dog feces, washed her hands and cleaned the house for hours if she believed she had been in contact with feces. Sometimes, thinking that a dark spot on the carpet was dog feces, she was seized by such panic that she was unable to move until her husband came home. If she did manage to reach the phone, her husband, a doctor at a hospital, had to go home and clarify the situation until the woman gradually calmed down. (p. 38)

On the other hand, Obsessive-Compulsive Personality Disorder has the essential feature of a pervasive pattern of perfectionism and inflexibility beginning in early adulthood and present in a variety of contexts (APA, 1980).

Obsessive-Compulsive Personality subjects constantly strive 
for perfection, but the adherence to their own overly strict and unattainable standards interferes with the actual completion of task and projects. Nothing is ever good enough for these individuals (Ingram, 1982).

It can be said that these individuals "can't see the forest for the trees" since there is often preoccupation with rules, efficiency, trivial details, procedures or form which interferes with ability to take a broad view of things. An example could possibly be a individual who has misplaced a list of things to be done, will spend an inordinant amount of time looking for the list rather than spend a few moments making another list from memory and finish the task. Time is usually poorly allocated with important tasks being left to the last moment (APA, 1980). The individual with obsessive-compulsive personaltiy disorder is interested in propriety, responsibility, conscientiousness, detail and in things being just right (Ingram, 1982). They are uncomfortable with generosity and mercy, instead wanting justice and lawfulness. If the obsessive-compulsive individual does show generosity or mercy, there is the secret feeling of getting a bonus for the display of extra goodness. This type of unconscious philosophy is buttressed by efforts which act to control, regulate, order, or organize. To the extent that these efforts produce the illusion of success, the compulsive 
maintains a feeling of mastery which, in turn, leads to a sense of superiority over others (Ingram, 1982). Individuals with obsessive-compulsive personality disorder have been shown to always be mindful of their relative status in dominance-submission relationships. Although they may resist authority they insist that others conform to their way of doing things (APA, 1980).

Horney (1950) reported that the obsessive-compulsive's sole reward for success is the pleasure of triumph. Professional success, financial independence and good health do not produce enjoyment. Efforts to be successful are urged on by the nagging sense that there is nothing without success. If the compulsive subjects fails to win success or keep up with some predetermined life schedule feelings or worthlessness begin to form in the psyche. A major depression may result or the subject may develop obsessivecompulsive disorders in which compulsive rituals are formed to reduce anxiety. Adler (1927) stated that the obsessivecompulsive is like a baseball player running from base to base being afraid of being tagged out. However, their game never ends.

For those who suffer from obsessive-compulsive personality disorder making a decision is a major ordeal. Decision making is avoided, postponed, or protracted, because of a fear of making a mistake (Ingram, 1982). Often 
there is a preoccupation with logic and intellect and intolerance of affective behavior in others. Assignments can't be completed on time because the person is ruminating about priorities. The indecisiveness may cause the person to keep worthless objectives even when they have no sentimental value (APA, 1980). Ingram (1982) has presented the hypothesis that patients are either indecisive or so clear and arbitrary that there is hardly ever a dilemma or question to which they don't know the answer immediately. Thus, they try to become incapable of puzzlement, bewilderment, and real wonder.

In connection with the issue of decisiveness it is important to keep in mind that obsessive-compulsive individuals run the gamut from passivity to intense aggression. Generally speaking more self-effacing compulsives are indecisive, whereas those who are more expansive will show greater arbitrariness and hence, decisiveness (Ingram, 1982).

Regardless of how indecisive the obsessive-compulsive individual may be, the uniform trait in the diagnosis of compulsive personality disorder is the quest for self control (Ingram, 1982). Horney (1945) wrote:

In a system so governed by rationality, the emotions are traitors from within and must be checked by unswerving control. Peace may be attempted but it is the peace of the grave. ( $p$. 138) 
It would appear that excessive self control is intended to block any contradictory emotions. Ingram (1982) wrote that self control becomes automatic and leads to suppression of enthusiasm and sexual excitement, as well as, allowing a departure from symbols associated with aliveness and vitality. For the compulsive subject any relaxation in self control and rational will can produce explosive feelings and impulses. Because they disrupt perceived reality, these feelings may be presented in the clinician's office as the fear of insanity (Horney, 1950).

People with the disorder are most certainly what we would consider "stingy" or "stiff". The DSM-III called them non-expressive in that they tend not to express their feelings and hardly ever give compliments or gifts (APA, 1980). Everyday relationships have a conventional, formal, serious quality. Ingram (1982) reported this resulted because striving to be perfect require adherence to a rational formula. All emotions need to be choked off, which creates a rather dry, serious and formal person.

For the obsessive-compulsive, work and productivity are prized at the exclusion of pleasure and interpersonal relationships (Salkovskis, 1985). Often there is a preoccupation with logic and intellect and intolerance of affective behavior in others (APA, 1980). The devotion to work is actually as much a means of avoiding situations 
calling for spontaneous feelings as it is necessary to achieve proof of worth. As the DSM-III (1980) reported, pleasure, if ever considered is something to be planned and worked for. However, the subject usually keeps postponing the pleasurable activity, such as vacations, etc., so that it may never occur (APA, 1980).

Having now considered both forms of obsessivecompulsive complaints, how are the two related? In classic psychoanalytic theory a spectrum is formed from obsessional traits to obsessional personality disorder to obsessive compulsive disorder (Deutsch, 1965; Salzman \& Thaler, 1981). All three are felt to reflect common ego defenses such as reaction formation, undoing and isolation of effect (Salzman \& Thaler, 1981). However, as Insel (1982) reported, just as conversion reaction does not equate with hysterical character the syndrome of obsessive-compulsive disorder does not always arise within an obsessional personality style. Nemiah (1975) estimated that $20 \%$ to $30 \%$ of patients with Obsessive-Compulsive Disorder lacked preexisting obsessional character traits.

Both disorders however display a preoccupation with aggression and control, both have the defenses of reaction formation, intellectualization, denial, and isolation of affect (APA, 1980). Psychoanalytic theory would suggest that Obsessive-Compulsive Disorder develops when these 
defenses fail to contain the subjects anxiety (Rosenberg, 1967). This would suggest that Obsessive-Compulsive Disorder is on some type of a continuum with obsessivecompulsive personality disorder. Some research would say otherwise. It has been reported that a substantial number of patients with Obsessive-Compulsive Disorder do not exhibit premorbid compulsive traits (Flament \& Rapoport, 1984; Kringlen, 1965; Lo, 1967).

In summary, confusion can be avoided if one remembers that patients with Obsessive-Compulsive Disorder have egodystonic symptoms, whereas obsessive-compulsive personality disorders are ego-syntonic, rarely provoke resistance, and are not usually associated with as great a sense of Compulsion (Insel, 1985). The DSM-III also lists certain subjective diagnostic criteria for both disorders.

According to the DSM-III (APA, 1980) ObsessiveCompulsive Personality Disorder is diagnosed as follows. A pervasive pattern of perfectionism and inflexibility, beginning by early adulthood and preset in a variety of contexts, as indicated by at least five of the following:

(1) perfectionism that interferes with task completion, e.g., inability to complete a project because own overly strict standards are not met

(2) preoccupation with details, 1 rules, lists, order, organization, or schedules to the extent that the major point of the activity is lost

(3) unreasonable insistence that others submit to exactly his or her way of doing things, or unreasonable reluctance to allow others to do 
things because of the conviction that they will not do them correctly

(4) excessive devotion to work and productivity to the exclusion of leisure activities and friendships (not accounted for by obvious economic necessity)

(5) indecisiveness: decision making is either avoided, postponed, or protracted, e.g., the person cannot get assignments done on time because of ruminating about priorities (do not include if indecisiveness is due to excessive need for advice or reassurance from others)

(6) overconscientiousness, scrupulousness, and inflexibility about matters of morality, ethics, or values (not accounted for by cultural or religious identification)

(7) restricted expression of affection

(8) lack of generosity in giving time, money, or gifts when no personal gain is likely to result

(9) inability to discard worn-out or worthless objects even when they have no sentimental value ( $p .247$ ).

The DSM-III provides the following subjective criteria for

the diagnosis of Obsessive-Compulsive Disorder.

A. Either obsessions or compulsions:

obsessions: (1), (2), (3), and (4):

(1) recurrent and persistent ideas, thoughts, impulses, or images that are experienced, at least initially, as intrusive and senseless, e.g., a parent's having repeated impulses to kill a loved child, a religious person's having recurrent blasphemous thoughts

(2) the person attempts to ignore or suppress such thoughts or impulses or to neutralize them with some other thought or action

(3) the person recognizes that the obsessions are the product of his or her own mind, not imposed from without (as in thought insertion)

(4) if another Axis I disorder is present, the content of the obsession is unrelated to it, e.g., the ideas, thoughts, impulses, or images are not about food in the presence of an Eating Disorder, about drugs in the presence of a Psychoactive Substance Use 
Disorder, or guilty thoughts in the presence of a Major Depression

Compulsions: (1), (2), and (3):

(1) repetitive, purposeful, and intentional behaviors that are performed in response to an obsession, or according to certain rules or in a stereotyped fashion

(2) the behavior is designed to neutralize or to prevent discomfort or some dreaded event or situation; however, either the activity is not connected in a realistic way with what it is designed to neutralize or prevent, or it is clearly excessive

(3) the person recognizes that his or her behavior is excessive or unreasonable (this may not be true for young children; it may no longer be true for people whose obsessions have evolved into overvalued ideas)

B. The obsessions or compulsions cause marked distress, are time-consuming (take more than an hour a day), or significantly interfere with the person's normal routine, occupational functioning, or usual social activities or relationships with others ( $p .247)$.

\section{Comparison with other Disorders}

In many cases obsessive-compulsive complaints are confused with other disorders. Here lies a key point of the study. Oftentimes obsessive-compulsive is used interchangeably with other terms which label psychiatric disorders. The DSM-III has made it clear that obsessiveCompulsive Disorder and Obsessive-Compulsive Personality Disorder are distinct disorders with their own diagnostic criteria.

In most cases, the symptoms of obsessive-compulsive disorders can easily be distinguished from those of other 
disorders attended by anxiety. Subjects may experience feelings of anxiety and panic when suffering from obsessiveCompulsive Disorders, but the diagnostic criteria given earlier from the DSM-III certainly act to facilitate the distinction.

Insel (1985) has stated that even though obsessiveCompulsive Disorder is classified as an anxiety disorder, anxiety may not be the primary feature. over the past years researchers have been intrigued by guilt, doubt, fatigue, indecisiveness and almost any other feature of the disorder except anxiety. It is interesting to note that in Europe, Obsessive-Compulsive Disorder is still considered an independent disorder with anxiety as a contributing but not defining symptom (Jablensky, 1985). The major problem lies in the fact that obsessive-Compulsive Disorder has many symptoms which overlap with other anxiety disorders, such as phobias.

Many times avoidance behavior displayed by obsessivecompulsive subjects may resemble phobia, and as a result, it becomes very difficult to make a diagnosis. An important difference between the phobic subject and the obsessivecompulsive subject is the success or failure of avoidance behavior in bringing relief from anxiety (Rachman, 1976). Hoogduin (1986) provides an excellent example.

The agoraphobic patient who stays at home can feel quite comfortable; an obsessive-compulsive patient 
suffering from fear of contamination may well stay home, but even then can still feel he may be contaminated by the air, water, food, contact with other people or contact with his own excreta. In other words, avoidance behavior is never as effective for the obsessive-compulsive patient as it is for the phobic patient. ( $p .43$ )

It is worth mentioning that obsessive-compulsive problems are often confused with schizophrenia. However, if the ego-syntonic and dystonic dichotomy is employed the differences are clearer. The schizophrenic patient suffers from delusions and the content of delusions is ego-syntonic, therefore, the patient is convinced of their truth (Hoogduin, 1986; Rudder, Gilmore \& Francis, 1982). This is in direct contrast to obsessional thoughts which are experienced as being ego-dystonic that result in the patient being bothered by them but also understanding they are external to the self. Persons with true delusions have a fixed conviction which cannot be shaken. For them the delusion is reality (APA, 1980).

Obsessive-Compulsive and Depression

One of the most disputed questions today in the Obsessive-Compulsive literature is whether or not obsessional disorders are a form of affective illness. This has been brought to the forefront because many obsessivecompulsives have been treated successfully with tricyclic antidepressants (Thoren, Asberg \& Cronholm, 1980), and the fact that major depressive episodes occur in at least $50 \%$ of 
Obsessive-Compulsive Disorder cases (Gittleson, 1966; Goodwin, Guze \& Robins, 1969). As Insel (1985) stated many obsessional patients only present themselves for treatment when they become acutely depressed. Even when they are not overtly depressed, affective like symptoms such as low selfesteem, guilt, exhaustion and indecisiveness are prominent. originally obsessional disorders were considered as a form of melancholia. Certainly today it can be seen that obsessional disorders may overlap with depression. However, as Lewis (1936) stressed, Obsessive-Compulsive Disorder is a depressing disorder, which brings a chronic state of hopelessness and helplessness. In a study by Insel (1982) all 20 subjects, without fail, reported feelings of depression at some point in the study of obsessivecompulsive patients. Two-thirds had depression ratings which would allow them to have been subjects in depression studies.

All the evidence could lead one to believe that Obsessive-Compulsive Disorder is simply depression with another name. This may be true in individual cases, but group data would not support the affective illness theory. As Corye (1981) reported, in contrast to affective illness, Obsessive-Compulsive Disorder tends to be more chronic, show a younger age of onset and has a lower ratio of female to male incidence. In fact studies have been reported where 
Obsessive-Compulsive Disorder subjects have a lower incidence of a family history of depression than general samples (Insel, Hoover, \& Murphy, 1983).

Perfectionism and Obsessive Compulsive Symptomology

In the past ten to fifteen years perfectionism has become a popular term in everyday conversation and in psychological literature. It would appear that perfectionism is a sub-category of what are now"known as Obsessive-Compulsive Disorders. The DSM-III has listed perfectionism as one of the diagnostic traits to look for in Obsessive-Compulsive patients.

What then is meant by perfection or perfectionism? Hamachek (1978) separates out what he calls normal and neurotic perfectionism. He notes that normal perfectionists:

are those who derive a very real sense of pleasure from the labors of a painstaking effort and who feel free to be less precise as the situation would permit. People like this want and need approval as much as anyone else. They interpret it as an additional good feeling on top of their own and use it as encouragement to continue on and even improve their work. ( $p, 27)$

Conversely, the efforts of neurotic perfectionists:

never seem to be good enough, at least in their own egos. They are unable to feel satisfaction because in their own eyes they never seem to be doing things good enough to warrant that feeling. (p. 27) 
Hamachack (1978) goes on to report that neurotic perfectionists demand a higher level of performance than is possible for them to obtain. They often feel anxious, confused and emotionally drained before they actually start to work on a particular task and are motivated not by a desire for success as they are by fear of failure.

Burns (1980) provides a similar definition:

Perfectionism is not the healthy pursuit of excellence by men and women who take genuine pleasure in striving to meet high standards. Perfectionists are those people whose standards are high. beyond reach or reason, people who strain compulsively and unremittingly toward impossible goals and who measure their own worth entirely in terms of productivity and accomplishment. For these individuals the drive to excel is selfdefeating. (p. 34$)$

There would appear to be a certain pathology involved in perfectionism. Cognitive researchers have found perfectionism to be a major feature in obsessive-compulsive and mood disorders (Beck, 1976; Burns, 1980; MCFal1 \& Wollersheim, 1979; Meichenbaum, 1974). These researchers present several cognitive patterns which are characteristic of obsessive-compulsive patients and those who are termed perfectionistic. First, dichotomous thinking is evident. Perfectionists tend to view life in a polarized fashion. Events are labeled "black and white," "bad or good," and underlying assumptions are in absolute terms as well, such as "all or none." 
Overgeneralization is another trait of perfectionist who illogically generalize on the basis of a single incident (Beck, 1976). A runner might feel one bad workout signals doom in an upcoming race if a perfectionistic thinking pattern was involved.

In the same area as overgeneralization lies an overly active system of self commands. These are termed by Horney (1950) as "the tyranny of the shoulds". She stated that the most common self commands are: "I should be the perfect parent, friend, etc.," "I should achieve all my goals." Dacht (1984) list other common shoulds such as: "I should be a better person," "I should have done it differently," "I should have worked harder." Weisenger and Lorenz (1981) continued on this mental distortion by saying:

The need to be perfect places a person in a self destructive double bind. If one fails to meet the unrealistic expectation, one has failed; but if one does meet it, one feels no glow of achievement for one has only done what was expected. There is no objective way to measure effort or improvement, no chance to relish success, no reason to build up ones self image. (p. 237)

Another trait found in perfectionists and obsessive compulsive suffers is an overly moralistic self-evaluation. Perfectionists measure their self worth in terms of unachievable goals of accomplishment and productivity, and any deviation from the perfectionists goal is likely to be accompanied by moralistic self-criticism and lowered selfesteem (Burns \& Beck, 1978). Horney (1950) wrote: 
When we think of perfectionistic people we often think merely of those who keep meticulous order, are overly punctilious and punctual; have to find just the right word, or find just the right necktie or hat. But these are only the superficial aspects of their need to attain the highest degree of excellence. What really matters is not those petty details but the flawless excellence of the whole conduct of life. But because all he can achieve is behavioristic perfection, another device is necessary. This is to equate in his mind standards and actualities in knowing about moral values and being a good person. (p. 196)

Ingram (1982) has stated that perfectionists are blind to the fact that knowing about moral values is not the same as being genuinely good. They may not see their imperfections, but may be blind, as well to how much they hate others for failing to live up to their standards. Horney (1950) emphasized the arrogance and contempt for others observed in the compulsive personality. This arrogance is an externalization of intolerable selfcondemnatory attitudes. Horney believes at the bottom, the perfectionist secretly fears that his/her moral perfection is false. By feeling "holier than thou," the individual acquires the right to look down on others and thereby inflict the same injury upon others as his parent inflicted upon him (Horney, 1937).

Many negative behavior patterns and emotional states have been attributed to perfectionist tendencies. According to Beck (1976), perfectionists tend to have disturbed interpersonal relationships related to anticipation of 
rejection when they inevitably fall short of their perfectionistic standards and a hypersensitivity to criticism and/or withdrawal from meaningful relationships. A vicious cycle is started when they notice, in fact, that no one is interacting with them and it is used as evidence of their own worthlessness and undesirability.

Burns (1980) reported that perfectionists tend to procrastinate, as they attempt to avoid the dreaded consequence of less than perfect performance. Also, Mahoney and Arnokff (1979) reported that dichotomous and overgeneralized thinking of the perfectionist is most detrimental to self-regulation of smoking, drinking, and eating habits. The first failure in the perfectionist plan is thought of as total failure which usually results in binge eating, drinking or smoking ("all or nothing" syndrome) .

Narcissism, Perfection and the Obsessive-Compulsive

Kohut $(1971,1979)$ has pioneered work on narcissism in which he contrasts neurotic disturbances with narcissistic personality disorders. His views necessitate considering a different concept of perfectionism with a different meaning than what has been discussed earlier.

Perfectionism in neurosis is a reaction to the demands of a harsh super-ego acquired as a result of learning and/or as a result of repressed hostility (Kohut, 1971). As such 
perfectionism is a defense against intrapsychic conflict and an attempt to retain the love of differentiated objects in the individuals "representational world" (Sandler \& Rosenblatt, 1962).

In contrast, perfectionism in the narcissistic personality is less related to morals and ideals. It is an attempt by the individual to live up to a grandiose selfimage in order to avoid humiliation and shame and the loss of admiration of poorly differentiated self objects (Kohut, 1971). The perfectionism serves to restore self and object representations and not to defend against intrapsychic conflicts as in neurosis. Therefore, the disturbance in self-esteem is the cause of the perfectionism and not the result of it (Sorotzkin, 1985).

Workaholism and Obsessive Compulsive

In the past decades the term workaholism has been identified as an important factor in the lives of many individuals especially those in professional occupations (Price, 1980). Very little research has been empirically reported on workaholism, therefore the area still requires further clarification as a concept.

Many definitions of workaholism connote a negative image. The word workaholism owes its origin, as well as its negative overtones, to alcoholism. What distinguishes workaholism from other dependencies is the fact that 
workaholism is often considered a virtue in our society, while others such as alcoholism or drug dependency are invariably considered vices (Machlowitz, 1980). Cherrington's definition (1980) captures this negative perspective best:

The central element defining a workaholic is an irrational commitment to excessive work. Workaholics are unable to take time or to divert their energy. These highly job involved employees may actually be obsessive-compulsive personalities in that their work "addictions" are symptoms of a felt necessity to control themselves and their environment and to avoid and suppress impulse and affect. (p. 257)

Obsession-Compulsion, when considered from a personality orientation, may be important in better understanding workaholism. Schwartz (1982) and Chonko (1983) have suggested that the concept of job involvement is related to obsession-compulsion. According to Schwartz (1982) highly job involved individuals tend to be no better or worse performers than non-job involved individuals. In addition highly job involved individuals have difficulty establishing effective work relationships with others. Chonko (1983) reported that job involved managers are more likely than non-job involved managers to be Machiavellian, to believe in the protestant work ethic, and to experience difficulty in dealing with others. This suggests evidence of potential overlap between job involvement and obsessioncompulsion. 
It would appear that some obsessive-compulsive individuals choose work behaviors as a way to manifest their obsessional tendencies. Hathaway (1984) suggested that it seems equally likely that non-job involved individuals may be compulsive in other areas besides their jobs. Hathaway goes on to theorize that some individuals may be highly committed to leisure activities (e.g., running) carrying them out with the same degree of intensity that would be expected of compulsive workaholics.

A typology of workaholism based on two key elements, those being commitment and obsession-compulsion is depicted in Figure 2 (Naughton, 1987). For the first type, the job involved workaholic, the long work hours and devotion to work and career reflect a like for work activities over other ones. Because of their low degree of obsessioncompulsion, combined with the high level of work commitment, job involved workaholics should perform well in demanding

Insert Figure 2 near here

jobs. In comparison for the compulsive workaholic, the addiction to work reflects a ritualized pattern of thinking and behavior. As a result considerable time and energy is expended on the job, but it is expended in a way that may be counteractive to actual work performance. Obsessive 


\begin{tabular}{|c|c|c|}
\hline \multirow{5}{*}{$\begin{array}{l}\text { Commit- } \\
\text { ment } \\
\text { to Work }\end{array}$} & JOB-INVOLVED WORKAHOLIC & COMPULSIVE WORKAHOLIC \\
\hline & High Job Satisfaction & Work Addict \\
\hline & $\begin{array}{l}\text { Low Interest in Non- } \\
\text { Work Options }\end{array}$ & $\begin{array}{l}\text { Potentially Poor } \\
\text { Job Performance }\end{array}$ \\
\hline & NONWORKAHOLIC & $\begin{array}{l}\text { COMPULSIVE NON } \\
\text { WORKAHOLIC }\end{array}$ \\
\hline & $\begin{array}{l}\text { Work as an } \\
\text { obligation }\end{array}$ & $\begin{array}{l}\text { Compulsively spends } \\
\text { time and energy in } \\
\text { non-work related } \\
\text { activities }\end{array}$ \\
\hline Low & Obsession/Comp & dision \\
\hline
\end{tabular}

Figure 2. Typology of Workaholism

From "A Conceptual View of Workaholism and Implications for Career and Counseling Research," by T. J. Naughton, The Career Development Quarterly, 1985, March, 180-187. 
-compulsive individuals may have difficulty relating to peers and especially to subordinates, who are the recipients of the tyranny and ritualized work behavior.

Two other types of workaholics are proposed to complete the typology. These categories include those individuals who have a low degree of commitment to work but who may vary in degree of obsession-compulsion. For nonworkaholics the low degree of commitment to work may be reflective of a performance for other things in life besides things at their jobs. Working is looked upon as a necessity to reach nonwork goals. In contrast, compulsive-nonworkaholics, although not committed to their work, participate in nonwork activities (e.g., running) in a compulsive manner. From this typology is evident that workaholism and/or obsessive-compulsive behaviors can play a very important part in how individuals perform in their careers whether they be business or athletic in nature.

In closing we may ask does workaholism represent a trait characteristic of the individual or is it situationally specific? Cherrington (1980) and Machlowitz (1980) suggested that workaholism is a long-lasting characteristic developed through childhood experiences in which work behaviors were reinforced by parents and other important others. Obsession-compulsion also appears to have 
its roots in early childhood experiences such as rigid and compulsive practices of parents (Pollak, 1979).

\section{Personality Factors in Obsessive Compulsive Disorders}

Many of the traits of obsessional personalities, such as, perseverance, industriousness, thriftiness, ambition, self control and so on, are highly regarded and rewarded within capitalistic, technological societies. They serve to promote feelings of self worth and acceptability, and provides a foundation for emotional stability and resistance to stress (Paykel \& Prushoff, 1979). In fact it could be argued that in western culture obsessive-compulsive traits (not disorders) are one of the main social character structures, which include the protestant work ethic and the capitalist economic system (Honnigman, 1967).

of special interest is the relationship of introversion and extraversion. Rosenberg (1967) found in a sample of obsessive-compulsive patients significantly lower than average scores both on the extraversion scale of the Maudsley Personality Inventory and on the second order extraversion of the Sixteen Personality Factor Questionnaire (Cattell \& Eber, 1957). Other studies by Forbes (1969) and Caine and Hope (1964) have found negative correlations up to -.80 between performance on the Hysteroid-obsessoid Questionnaire (Caine \& Hawkins, 1963) and performance on the extraversion scale of the Sixteen Personality Factor 
Questionnaire in psychiatric and nonpsychiatric samples, with subjects classified as obsessional consistently scoring significantly lower on the extraversion measures than subjects who were classified as hysteroid. Rinieris, Stefanis, and Rabavilas (1981) also found a negative relationship between obsessive-compulsive subjects and extraversion as measured by the Eysenck Personality Inventory. The results of these studies would suggest obsessive-compulsive subjects are highly related to the introversion extreme on the introversion-extraversion continuum.

Interesting comparisons can be seen in runners when looking at the introversion-extraversion continuum. Morgan (1978) reported that the large body of literature in sport psychology suggest that runners are more introverted than team sport athletes. Employing the IGPF (Cattell \& Eber, 1957) Neiman and George (1987) reported that in a sample of 231 runners there was a strong introversion characteristic present. This is in agreement with Gontag (1978) who found twice as many introverts as extroverts in a group of fifty marathoners. Morgan (1972) also found that marathoners were characterized by introversion. Whether these characteristics in runners are due to self selection or the effect of years of running will need to be demonstrated with future research (Morgan, 1978). It is interesting to note 
however the similarities on intraversion-extraversion measures between obsessive-compulsives in the general population and runners.

Obsessive-Compulsive, Addiction and Running Commitment

The terms addiction, obsession, compulsion, habitual, committed, and obligatory, have all been used interchangeably in the past few years when discussing behavior patterns, whether it be drug use, sex, exercise, house cleaning, etc. The word most often used to describe a regular behavior pattern has been addiction. Is addiction the same as obsessive-compulsive or commitment? The literature would clearly point to this not being the case.

The previously discussed definitions of obsessivecompulsive disorders describe a thought-behavior pattern much different from the classical definition of addiction. In defining the concept of addiction Peele (1985) stated:

an addiction exists when a person's attachment to a sensation, an object, or another person is such to lessen his appreciation of and ability to deal with other things in his environment, or in himself, so that he has become dependent on that experience as his only source of gratification. (p. 420$)$

In fact, strictly speaking addiction is a state of physiological dependence on a specific substance arising from the habitual use of that substance (Wedin, 1984). Hoogduin (1986) stated that an addiction results when a 
person repeatedly uses external substances to bring about changes in his psychological state.

The DSM-III delineates between true compulsions and addictions or dependencies (APA, 1980). The DSM-III states:

Some activities, such as eating (e.g., Eating Disorders), sexual behavior (e.g., paraphilias), gambling (e.g., Pathological Gambling), drinking (e.9., Alcohol Dependance or abuse) or drug use (e.g., Drug Addiction), when engaged in excessively may be referred to as "compulsive". However, the activities are not true compulsions because the person derives pleasure from the particular activity, and may wish to resist it only because of its secondary deleterious consequences. (p. 246)

In summary this clearly suggests there is a psychological difference between obsessive-compulsive disorders and addiction. For addiction to occur the activity itself must be pleasurable, however, for obsessivecompulsives the activity itself may not even be considered pleasurable. The activity simply serves to reduce anxiety in the individual. In fact the World Health organization has even suggested dropping the terms drug addiction in favor of the term dependence (Worick and Schaller, 1977), in part due to the frequency of the inappropriate use of the word addiction. The term addiction remains in extensive use today to describe the involvement runners have with their activity, but based on the preceeding definition runners do not appear to be really addicted. 
The concept of being addicted to exercise, although only recently popularized, has gained widespread acceptance, especially among runners (Sacks \& Sachs, 1981). It would appear that the perception of being addicted to exercise has become part of the runners self concept and is almost expected of those who consider running to be the most important thing in their lives (Carmack \& Martens, 1979). It is interesting to note that most of the exercise addiction ideas came out of work by an author who did not employ any empirical research. Glasser (1976) wrote Positive Addiction in which he examined "addictions" which support an addict's psychology and physiology. For Glasser positive addictions, such as running, are thought to promote psychological strength and increase life satisfaction. However, Glasser's work is not scientifically based in that it did not incorporate experimental design, descriptive data or statistical analysis.

Research on running addiction appears to have started with Baekeland in 1970. Baekeland (1970) wanted to study exercise deprivation, but he couldn't get people to stop exercising even if he paid them. However, this does not define the potential subjects as being addicted to exercise.

Other studies have attempted to examine the psychological characteristics of exercise addicts. Sachs and Pargman (1979) attempted to study runners at various 
stages of addiction. Through their work Sachs and Pargman identified certain characteristics which define running addiction. They defined running addiction as:

a psychological and/or physiological dependency to a regular regiment of running in which withdrawal symptoms occur after twenty-four to thirty-six hours without the activity.

These withdrawal symptoms appear to be the critical idea in determining so called running addiction. For Glasser (1976) these withdrawal symptoms include anxiety, guilt, restlessness, depression, irritability and tension. Some runners reported apathy, sluggishness, lack of appetite, sleepiness, and headaches. It is interesting to note that running serves to reduce the anxiety of these running "addicts" just as compulsive activity and behaviors reduce the anxiety of those individuals with obsessive-Compulsive Disorder.

Withdrawal symptoms are seen as a negative aspect of running. Harris (1981b) tested 156 women and questioned them about their feelings during a period of time when they had stopped running. Only 10.3 percent of the women had never stopped running. of the rest $71.4 \%$ felt less energetic, $67.9 \%$ felt guilty, $67.9 \%$ felt fatter, $40 \%$ felt depressed and $38.6 \%$ felt tense when they stopped running. The negative reports were far more frequent than the positive ones of feeling relieved (2.1\%), thinner (1.4\%), relaxed $(1.4 \%)$, or more energetic $(0.7 \%)$. In both this 
study and another by Harris (1981a) there was a preponderance of negative feelings correlated with not running. However, it is uncertain if they felt this way before they started running.

Although reports have indicated high levels of such withdrawal symptoms as anxiety or guilt in people deprived. of running, it is possible that they will not be reported as so intense on paper-pencil instruments (Sacks and Sachs, 1981). Furthermore, Robbins and Joseph (1980) have suggested that some symptoms may be more frequently reported because articles on exercise addiction in popular literature lead runners to believe they should experience certain symptoms if they don't run. This is what Robbins and Joseph have termed the "Runner's World" effect.

Withdrawal symptoms can be explained from a number of different points of view. Robbins and Joseph (1980) have suggested two such explanations for withdrawal symptoms. The first is withdrawal symptoms indicate insufficient stress reduction or incomplete stress avoidance when a run is missed. The researchers go on to suggest that for some people running masks sensations of stress; but as long as the stressor remains running will only mask them and they will be felt again when running stops. This is an interesting thesis by Robbins and Joseph (1980), however, the so called sensations of stress could actually be 
obsessions and the running is the compulsive activity which reduces these obsessive thoughts. On the other hand these runners may simply be very committed to health and exercise and may be so in tune with their bodies that any change in sensation is exaggerated. Robbins and Joseph (1980) go on to report that runners may face a danger in that exclusive reliance on running may cause other coping mechanisms to atrophy, leaving the runner without any means of handling stress when running is not possible, such as with an injury. This would also be true if obsessive thoughts invade the runner's thinking. If anxiety reduction comes through compulsive running then being unable to run can mean negative consequences for the obsessive-compulsive runner. Robbins and Joseph (1982) also reported that fewer symptoms of distress were felt by runners who used running primarily as an escape than by those who used running as a major coping mechanism. They theorize that escape is a means of avoiding the stresses of life, but these stresses will not necessarily be present whenever the person cannot run. On the other hand for those who use running to reduce the effects of general stressors an inability to run means that the effects are not reduced, so it could be hypothesized that distress would increase. Again, we must ask are the "coping" runners really obsessive-compulsive runners? 
Carmack and Martens (1979) examined running commitment which Sacks and Sachs (1981) viewed as the same as running addiction. Runners who score higher on a measure of commitment to running reported greater psychological discomfort when they missed a run, had a high level of perceived addiction and ran for longer periods on their regular runs. In the study runners tended to give psychological reasons for continuing to run. Running commitment is therefore a psychological drive or need which motivates individuals to run. Running commitment can be predicted by such factors as length of run, discomfort experienced when a run is missed, and perceived addiction to running. It would appear that running addiction and commitment as defined by Carmack and Martens (1979) are very similar.

Researchers have attempted to develop a set of traits which could predict running addiction. Sachs (1981), Sachs and Pargman (1979) and Jacobs (1980) have all attempted and failed to uncover a personality profile of addicted runners or to construct a descriptive classification of the addiction process. At present there would appear to be no way to predict who will become addicted or identify the environmental or situational factors critical to the development of addiction. 
Carmack and Martens (1979) and Summers, et al. (1983) provide data pertaining to gender comparisons on the Commitment to Running scale. Carmack and Martens generally found that males score higher on the Commitment to Running Scale than females, however, no sex differences were found when only runners who averaged more than forty minutes per run were considered. In the summers study no differences were found for Commitment to Running scores for males and females, however, females perceived themselves as more addicted to running and had more withdrawal symptoms when unable to run than did males. Masters and Lambert (1989) have reported that females scored higher on the commitment to Running Scale than males and also had a higher level of perceived addiction. From this research it would appear that females could possibly be considered more addicted to running than males.

Persons more addicted to running could be expected to demonstrate their addiction by their behavior (Masters \& Lambert, 1989). The more addicted they are the more they might be expected to train. This theory was supported by Masters and Lambert's:(1989) research. This was found to be more significant in male runners who were found to actually run significantly more miles and went on longer training runs than females. 
One theory of running addiction has come from the physiological components of exercise. Researchers speculate that during exercise, endorphine levels increase (Farrell, Cates, Maksud, Morgan \& Tseng, 1981), decreasing anxiety (Pargman \& Baker, 1980), and mediating a sense of well being (Stein \& Gelluzzi, 1978) hence, the runner becomes addicted. It is speculated that when running is terminated for a period of time, these endorphine levels decrease and the runner experiences withdrawal symptoms which are reported as feelings of anxiety, irritability and depression (Crossman, Jamieson and Henderson, 1987). However, the proposed relationship between endorphine levels, mood swings and running addiction has failed to be consistently demonstrated in controlled scientific studies (Hawley \& Butterfield, 1981). Weisz and Thompson (1983) summarized theories relating endorphines and addictive behaviors and reported there was not sufficient evidence to conclude that endogenous opiods mediate any addictive process.

\section{Addiction in Runners}

For most runners the activity of running represents a very healthy habit. However, Sachs (1981) has stated that running can become a "compulsion", a "habit", an "addiction". Running can become not merely a means to the end of getting in shape, but the end it self. The need to run may become constant. For a small number of runners 
running begins. to control their lives, eliminating other choices. Morgan (1979) had presented evidence noting that the development of exercise addiction does not differ from addictive processes in general. Morgan cites a number of case studies of runners who are virtually consumed by the need to run. These runners dramatically alter their daily schedules, continue to run even when seriously injured, and neglect the responsibilities of work, home, and family. However, are the runners Morgan talks about really addicted or do they suffer from a form of obsessive-compulsive disorder? There is no empirical evidence.

Runners may actually recognize negative symptoms in themselves or other runners. The toll of strenuous training may show itself in decreased ability to concentrate, listlessness, fatigue, impaired social activity and work productivity and other signs. More obvious symptoms include skipping appointments because of the need to run (Sachs, 1981).

Sachs (1981) goes on to point out that because runners tend to be well educated, many addicted runners can acknowledge these symptoms and recognize the effects of running on their lives. Furthermore Sachs points out that researchers must be aware of the implicit moral judgment which is made here. Given the above described characteristics one could suggest certain criteria for 
determining whether a person is addicted to running. But if an individual is "diagnosed" as addicted, is this necessarily negative? Maybe they are just committed to high levels of performance or good health.

Many runners may be analytical and introspective enough to know, that even though running may dominate their life, it may still indeed be a positive. Some runners however may not realize running can pass from dedication to obsession (Waters, 1981). Waters believes that for most runners this transition from positive to negative addiction is temporary. Most runners find it uncomfortable and are forced to reorder their priorities. This may be true for the greatest percentage of the running population, but there certainly are a large number who do not comprehend the level of their involvement or realize the extent to which running controls their lives (Waters, 1981).

\section{When Runners Can't Run}

What then happens to the addicted runner who can't run? This will usually occur as a result of a serious injury which forces the addicted runner to stop. Little (1979) reported on what he termed "the athlete's neurosis". In a sample of forty-four running subjects, an illness or injury had initiated a neurotic breakdown in $72.5 \%$ of cases, while in twenty-eight neurotics who were non-runners physical 
threats preceeded the onset of symptoms in only $10.7 \%$ which was a highly significant difference.

In the great majority of athletic subjects the neurotic symptoms developed almost immediately after injury. Little went on to report that the "athlete's neurosis" can, and usually does, provoke prolonged and crippling psychological, domestic and economic strains, as many of the subjects remained unemployable for years. obviously there would appear to be something here of concern for all runners. Sachs and Pargman (1979) have proposed a model to clarify motivation to running which is similar to the Typology of Workaholism model by Naughton (1987) which was discussed earlier in the review. In Sachs and Pargman's (1979) model (see Figure 3) two axes are conceptualized, one indicating addiction, and the other cognitive intellectual commitment, speculating that motivation for running is best examined through a two factor rather than a unidimensional model.

Insert Figure 3 near here

Four quadrants were proposed to define the relation of commitment to addiction, each hypothesized to categorized a different "type" of runner (Sachs \& Pargman, 1979). The truly addicted exerciser, found in quadrant $A$ is 


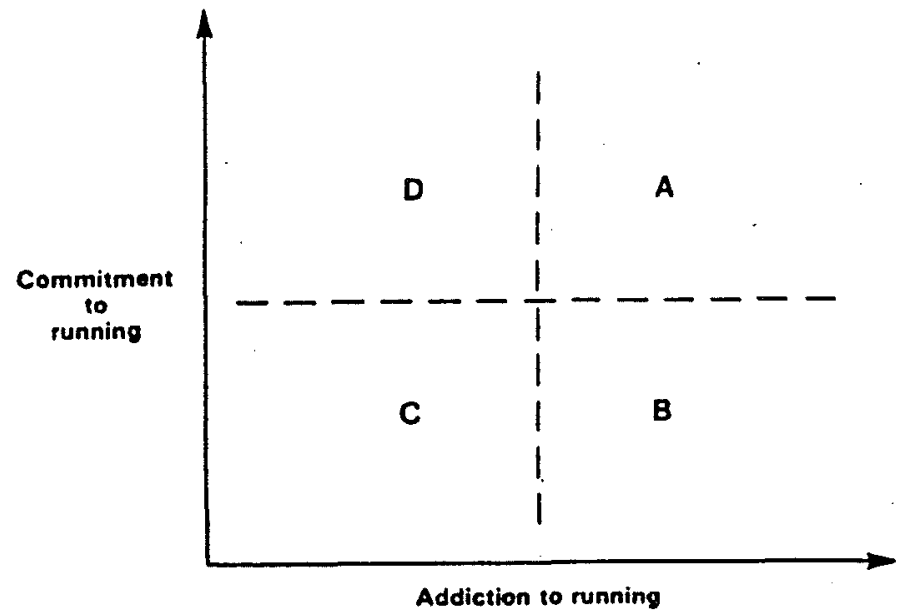

Figure 3. Model of Participation in Running

From "Running Addiction: A Depth Interview Examination," by M. L. Sachs and D. Pargman, Journal of Sport Behavior (1979), 2: 143-155. 
characterized by both high levels of commitment and addiction. This runner's lifestyle centers on regular running, and motivation factors have progressed beyond interest in keeping in shape or losing weight. These runners seek psychological well being through running and also try to avoid the withdrawal symptoms of long layoffs. An individual who is addicted to running but not totally committed to a regular schedule would be in a quadrant B. Social agents such as family, work, or school may take priority over running, but addiction is still characteristic of those in the B quadrant. Quadrant C contains the occasional runner, characterized by low levels of commitment and addiction. This person may feel some guilt if running is not possible but does not suffer withdrawal symptoms of the addicted runner. This runner will run occasionally, when convenient and on no set schedule.

Runners in quadrant $D$ are unusual because little is known about them. These runners are highly committed but not addicted to running. They remain committed for health and social reasons that may have initially motivated them. Quadrant D runners do not run for mind bending experiences, euphoria, or an escape from depression. Their motives include health and social reasons, money, (athletic scholarships, prize money) prestige and power. 
The proposed model by Sachs and Pargman (1979) is dynamic in nature with potential movement through its quadrants, but this movement does not occur freely. According to the researchers there appears to be a patterned direction of change in location within the model as is illustrated in Figure 4.

Insert Figure 4 near here

According to Sachs and Pargman all runners begin in quadrant $\mathrm{C}$ with low levels of commitment. Before addiction can increase commitment must increase. As a result movement from quadrant $C$ can only be through to quadrant D. From quadrant $\mathrm{D}$ runners can move to quadrant $\mathrm{A}$ or $\mathrm{C}$. As commitment remains high, addiction to running may develop and the runner moves to quadrant $A$. If commitment should decrease movement goes toward quadrant $C$, with a low level of addiction and commitment decreasing from high to low. Movement from quadrant $A$ can only be to quadrant $B$. Addiction will not decrease unless commitment first decreases and withdrawal symptoms occur. As commitment decreases the runner moves into quadrant $B$.

The runner in quadrant $B$ will show a decrease in addiction and move to quadrant $c$. At this time there are 


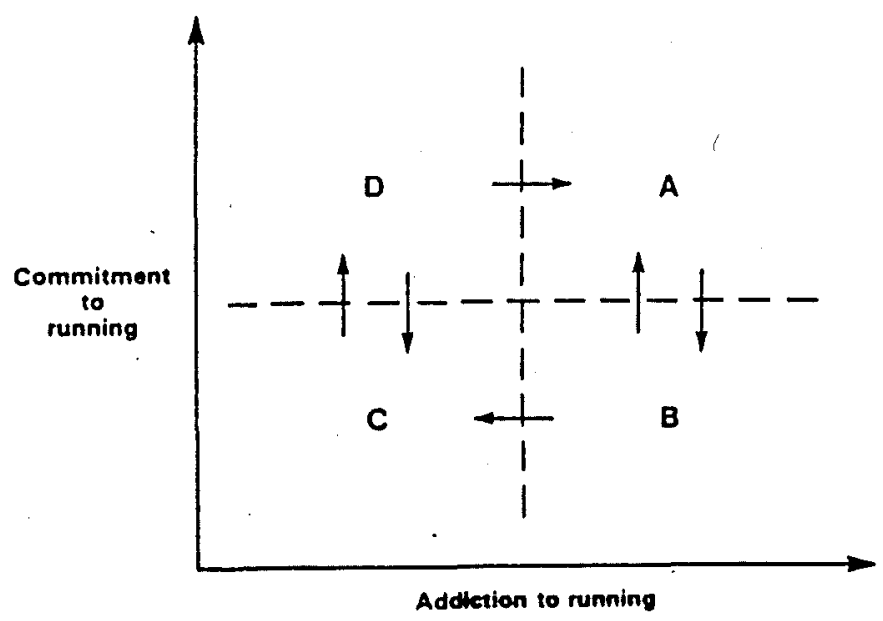

Figure 4. Movement Patterns in the Model of Participation in Running

From "Running Addiction: A Depth Interview Examination" by M. L. Sachs and D. Pargman, Journal of Sport Behavior, (1979), 2: 143-155. 
two possibilities for movement. If commitment remains low, addiction will continue to decrease and the runner will stay in quadrant $C$. If commitment increases however, the runner will return to quadrant $A$.

The position of the runner in quadrant $B$ is unstable and this point has been reinforced by Sachs and Pargman's (1979) research. They found that the type B runners had the greatest mood change among runners in the four quadrants on a day when subjects couldn't run. Despite the dynamic quality of the model, runners in quadrants $A, C$ and $D$ tend to remain stable unless there are changes in motivation, with concomitant shifts in level of commitment or development of addiction. Position in quadrant $\mathrm{B}$ tends to be associated with being unstable, since low levels of commitment do not appear to be associated with high levels of addiction for longer than a few days or weeks.

In summary the model provides a beginning framework on how running addiction may first develop and then progress. However, as Sachs and Pargman (1979) have pointed out, there is concern that the term addiction may be inappropriate since its "strict" definition has been turned into a type of "hybrid" for use with runners and other exercisers.

Drawing a comparison from sexual addiction, Wedin (1984) reports why "sexual addiction" is not a form of addiction. According to Wedin, addiction is a state of 
physiological dependence on a specific substance arising from the habitual use of the substance and sex is an experience, not a substance. Although sexual experiences may be "mood altering", sudden withdrawal from sexual behavior doesn't lead to physiological distress such as diarrhea, delirium, convulsions, or death. Vomiting induced by fear of giving up a learned pattern for dealing with anxiety (such as having sex or running) is not the same thing, according to Wedin, as vomiting induced by physiological withdrawal from an addicting substance.

In addition, as professionally conceptualized, sexual addiction is currently the only type of "addiction" in which the addict is not expected to give up his or her "drug" of choice as part of the "treatment" (Schwartz \& Brasted, 1985). The same could be said for the so called running "addict". Do you "treat" the person by forcing them to abstain from running totally? As Carnes (1983) has suggested addiction is a classic instance of moral judgment parading around as a scientific fact. Could this be said for running addiction as well?

\section{Measurement of Obsessive-Compulsive Personality and Running Addiction}

Until recently very little importance was placed on the diagnostic procedures used to evaluate Obsessive-Compulsive Disorders. Clinical symptoms were used to determine the 
diagnosis. Now, however, a shift has been made toward the use of assessment instruments.

The earliest psychological instruments used to measure obsessive-compulsive traits included the Minnesota Multiphasic Personality Inventory (Hathaway \& Mckinley, 1951), the Cornel1 Health Questionnaire (Brodman, Deusstchenberger \& Wolff, 1956), and the Maudsley Personality Inventory (Eysenck, 1959). All of these instruments contain several items which remotely pertain to obsessional or perfectionistic traits, but none are designed specifically to cover the wide range of traits of obsessivecompulsive problems.

In 1968 Cooper and McNeil conducted a study of so called house-proud mothers. To assess the house-proud traits of housewives, Cooper developed a questionnaire, assessing the severity of the mother's degree of obsessionality. As a result of the study the Leyton Obsessional Inventory was constructed. The inventory is based on a card-sorting procedure which requires a yes-no reply to 69 questions. Although unintentional, it has been used in clinical settings because, as compared to previously published questionnaires, it gives a more detailed and extensive coverage of obsessional complaints. However, it would appear to have drawbacks as Cooper (1970) has 
suggested. It takes up to two hours to administer plus no validity or reliability has been established.

Allen and Tune (1975) modified the Leyton Obsessional Inventory and developed the Lynfield Obsessional-Compulsive Questionnaire. Items were added in order to increase the range of possible responses and to increase the change score after treatment. The 20-item questionnaire has no reported reliability and the validity of the test is based upon its correlation with the Leyton Inventory, which has no reported validity itself.

Caine and Hawkins (1963) developed the HysteroidObsessoid Questionnaire to measure just that; hysteroid and obsessoid personality characters. The rationale for its development was based on the theory which claimed hysteroid and obsessoid were the two polar personality types. The test is rarely used because there is no validity or reliability reported with obsessive-compulsives used as subjects.

Hodgson and Rachman (1977) designed the Maudsiey Obsessive-Compulsive Inventory to look at types of obsessive-compulsive disorders. The researchers developed a large pool of items based on published research and their own clinical experience. Thirty items were discovered to discriminate between obsessions and overt rituals, and other introverted neurotics with obsessional complaints. The 
items are true-false and have been tested on obsessivecompulsive patients. Validity .60 of the MOC was obtained by correlation with the Leyton Inventory, which as mentioned, really has no validity. only test-retest reliability is reported on normal night school college students.

Gibb, Bailey, Best and Lambirth (1983) have developed a 22-item scale which uses a true-false response set to measure obsessive-compulsive personality disorder. A score of between 0 and 20 results with the remaining two items used as subscale for validity of response. The ObsessiveCompulsive Scale has a test-retest reliability coefficient of .82. Concurrent validity was reported at .79 between clinicians' evaluation and clients' scores on the scale. In conclusion Philpott (1975) has indicated that there are three major problems in the assessment of obsessional disorders (See Figure 5). It is for these reasons that it has been difficult to construct good measuring instruments.

Insert Figure 5 near here

As far as running addiction measurement the choices and quality of instruments is even more limited than in the Obsessive-Compulsive field. The most popular instrument for measuring running addiction is the "Feelings about 
Effect

1. Multiplicity and wide range of symptoms and disabilities

2. Complex relationship with both anxiety and depression

3. Rarity of patients with obsessional neurosis account for only $1-3 \%$ of new outpatient attendances
1. Tends to render comprehensive questionnaires unwieldy and nexible individual measures unreliable between patients or studies

2. Contaminates results of treatment espectially treatment with antidepressants; also contaminates assess ment measures

3. Unlikely that single-center studies will accumulate sufficient patients for randomization in controlled treatment trials

Figure 5. Major Problems Involved in the Assessment of Obsessional Illness

From Recent advances in the behavioral measurement of obsessional illness difficulties common to these and other measures by Philpott, R., Scottish Medical Journal, 20: 3344 . 
Running Scale" developed by Carmack and Martens (1979), which rates "commitment" to running. For Sachs (1981) the commitment in the "Feelings about Running Scale" is the same as running addiction. Sachs reports that the scale asked subjects how they feel most of the time toward twelve statements about running employing a five point scale from 1 (strongly disagree) through 5 (strongly disagree). The scale has been found to have inflated scores with runners which would lead one to believe that there is some desirability or demand factor in the scale. Possibly runners may agree with statements about running, perhaps to avoid appearing to not really like an activity in which they are deeply involved with (Carmack \& Martens, 1979). However, Carmack \& Martens (1979) report a reliability coefficient of .93 with a mean inter-item correlation of .30. Employing Kuder-Richardson Formula 20 a reliability coefficient of .97 was calculated. Concurrent validity was reported in the form of regression analysis with $42 \%$ of the variance being explained by four factors.

Thaxton (1982) has raised doubts that the "Feeling about Running Scale" even measures anything close to addiction. He found that the Commitment to Running score was not significantly correlated with a measure of perceived addiction. Plus, measures of running involvement (race frequency and best race times) correlated only with 
Commitment to Running Score and not with perceived addiction. Thaxton also found some subjects with high scores on the "Feelings about Running Scale" who reported they were not physically and psychologically dependent on running and never experienced withdrawal. This would suggest that the"Feelings About Running Scale" may not actually measure any kind of dependency or addiction to running.

Several other instruments have been developed to look at running addiction. Joseph and Robbins (1981) attempted to incorporate the measurement of addiction to running into their "Running Survey". Unfortunately, no reliability or validity information has been published for the instrument. Sachs (1981) has developed an instrument to measure runners' withdrawal symptoms, but again no validity or reliability is reported. Hailey and Bailey (1982) have developed an instrument which may come closer to getting at running addiction than other test. Based upon face validity their addiction scale would appear to have at least begun to measure addiction. However, no reliability and validity has been reported.

In conclusion it would appear that the instruments which supposedly intend to measure running addiction, running commitment and obsessive-compulsive disorders may not actually measure the constructs which they report to 
measure. As a result, many of the psychological terms in the literature are used in appropriately and out of context. The inappropriate use of terms has led to much of the preser confusion in the sport psychology literature when discussing running psychology. The present study is intended to address this confusion and bring the terms into proper usage.

\section{Summary}

In conclusion the literature presented in this chapter has provided a background for looking at obsessiveCompulsive disorders as they relate to running addiction and commitment. The chapter has provided a focus on obsessivecompulsive disorder and how they compare with other similar, yet different disorders which are inappropriately grouped together in much of sport psychology literature. Measurement techniques were also addressed.

Before athletes can be counseled there must be sound assessment procedures employed to provide the sport psychologist with the proper perspective from which to work. Through the current research effort it is hoped that the gray area that exists between running addiction, commitment and obsession-compulsion can be brought into the proper focus so that sport psychology professionals may accurately assess runners and their running behaviors. 
CHAPTER III

METHODOLOGY

In order for research to provide meaningful and generalizable findings it must be based upon a sound design. The design should provide the following basic structure:

1. Identify key variables or constructs which are acting in the process understudy.

2. Develop appropriate research questions.

3. Decide upon data collection methods.

4. Establish methods of data analysis.

5. Discuss and evaluate the research study.

This study was designed to study the relationship

between obsessive-compulsive personality, running addiction, and commitment to running as measured by three paper-pencil instruments. Relationships of the three measures were also examined in comparison to age and sex. Drawing from the research literature previously cited it can be hypothesized that one underlying factor is in operation between obsesesive-compulsive personalities and what the literature has termed "running addiction" and "commitment to running." Without appropriate assessment techniques and diagnostic methodology sport psychology 
professionals will be unable to effectively differentiate these constructs when they do exist and, as a result, will be unable to effectively counsel or refer runners to clinical psychologists for treatment when they present symptoms of abnormal exercise and/or running behaviors.

\section{Instrumentation}

To gather the necessary and appropriate data for generating answers to the research questions a means for measuring obsessive-compulsive personality, running commitment and running addiction had to be selected. As noted earlier in the review of literature a number of paper-pencil type instruments were available for this purpose.

objective, paper-pencil type instruments would best serve the purpose of the research study in the most efficient and effective manner. Since paper-pencil survey research instruments allow for distribution to a large number of runners in a short period of time, over a large geographical area, they were deemed as the most appropriate means for gathering data.

\section{Obsessive-Compulsive Personality}

To decide upon a measure of obsessive-compulsive personality the available instruments were reviewed for appropriateness for the study, ease of mail survey 
research administration, and validity and reliability. The MMPI and Maudesly Personality Inventory (Eysenck, 1959) were ruled out because even though they contained several items pertaining to obsessional-compulsive traits, none gave complete, isolated coverage to the obsessivecompulsive phenomena. The Leyton obsessional Inventory (Cooper \& McNeil, 1968) was not suitable because it employed a card sorting procedure which required a testing agent and takes up to two hours to complete. Also no validity and reliability had been determined for the instrument.

Another instrument popular in the research which was deemed inappropriate was the Lynfield obsessionalCompulsive Questionnaire (Allen \& Tune, 1975). This instrument reported validity, however it was based upon correlation with the Leyton inventory which reported no validity.

Hodgson and Rachman (1977) developed the true-false Maudsley Obsessive-Compulsive Inventory. Its 30-item format was attractive yet it reported no validity or reliability. In fact the validity and reliability of all obsessive-compulsive measuring instruments was found to be lacking. Buros (1974) has not listed a single instrument to report high validity or reliability coefficients in the area of obsessive-compulsive research. 
All things considered the Obsessive-Compulsive Scale (OCS) (Gibb, Bailey, Best, \& Lambirth, 1983) was chosen for the study. The Obsessive-Compulsive Scale (OCS) (see Appendix A) contained twenty-two forced choice items responded to as true-false. To avoid a response set, ten items are scored positively if responded to in the affirmative; and ten scored positively if responded to in the negative. Thus a score between 0 and 20 for a compulsivity construct was possible with the higher score indicating a higher degree of obsessive-compulsive personality. The remaining two items are a subscale for validity or invalidity of responding (see Appendix A). The test-retest reliability coefficient of .82 $(p<.001)$ indicated that the ocs exhibits what could be considered at least an acceptable level of reliability. Validity was determined by having clinicians assess the degree of each clients obsessive-compulsive traits. Clinicians determined their evaluations without the knowledge of how a particular client scored on that ocs. Clinical ratings were then correlated with client scores and the OCS. Client's roommates were also asked to rate the degree of obsessive-compulsiveness of their roommates. The ocs scores were then correlated with roommate evaluations.

The correlation between clinician's evaluations and client's scores on the ocs was .79 ( $p<.0001)$, and the 
correlation between client's scores and roommate evaluations was $.45(p<.0001)$. It was expected that clinical ratings would be correlated with ocs scores to a greater degree than roommate evaluation scores, as clinicians are more highly trained and experienced in the assessment of personality. The data demonstrated that the ocs is a useful research/clinical instrument in the assessment of obsessive-compulsive personality. Therefore, the ocs was the instrument of choice in measuring Obsessive-Compulsive Personality in the current research project.

\section{Running Commitment}

For running addiction and running commitment the choices for an effective measuring instrument were again limited by reliability and validity constraints. The most popular instrument for measuring commitment to running is the "Feelings about Running Scale" developed by Carmack and Martens (1979) which rates commitment to running. Sachs (1981) suggested that even though it measured commitment, the construct of running addiction is so much alike that the Feelings about Running scale could also be used to measure running addiction. Carmack and Martens (1979) preferred to employ the term commitment over the popularized phrase of "running addiction." This choice was based upon a previous review of literature by the 
authors. In the development of the instrument carmack and Martens (1979) reported a reliability coefficient of .93 with a mean inter-item correlation of .30. KuderRichardson formula 20 was then applied and a reliability coefficient of .97 was calculated. Concurrent validity was reported in the form of regression analysis results with $42 \%$ of the variance being explained by four variables which were perceived addiction to running, two factors on psychological well being and average distance run. Because of the reported reliability and validity and the fact that the commitment to Running scale has been noted to measure running addiction as well, it was felt the scale would be an appropriate and useful instrument to employ in the research study and would be used along with a specific scale on running addiction (see Appendix C). The Commitment to Running scale consisted of 12 items scored on a five point rating scale from 1, "strongly disagree" to 5 "strongly agree". Five of the items were scored in reverse with title "Feelings About Running" being employed to minimize possible response bias.

Other instruments such as the "Running Survey" by Joseph \& Robins (1981) and an instrument which measures withdrawal symptoms from running addiction by Sachs (1981) were deemed inappropriate for use since they are difficult and very time consuming to administer. 
Running Addiction

Based upon the previously reviewed literature, an instrument developed by Hailey and Bailey (1982) was deemed most appropriate for measuring running addiction by the investigator, as well as, an educational research specialist (see Appendix B). The Negative Addiction Scale best approached the construct of running addiction which was described in the literature. The items of the Negative Addiction Scale best measured the withdrawal symptoms which define running addiction based upon Glasser (1976) and Sachs (1981) writings.

The Negative Addiction Scale however has failed to report any validity or reliability except face validity. Face validity however was determined by review of an educational research specialist, a college track coach, and four nationally ranked marathon runners in the United states. These individuals at a major east coast university reviewed the scale and all agreed that as running addiction is described in the popular literature, the Negative Addiction Scale did offer questions related to running addiction.

The lack of reported reliability and validity may be considered a detrimental aspect. Unfortunately, there were no identifiable assessmsent instruments for running addiction which report any validity except the commitment 
to Running Scale (Carmack \& Martens, 1979) which does not specifically measure addiction. In fact there are limited reports of any efforts to actually validate running addiction scales. Masters and Lambert (1989) attempted to provide construct validity between the commitment to Running Scale and running addiction based upon correlations with training variables and did report positive relationships between Commitment to Running scores with training hours, years, and miles. These results do provide support for the construct of running addiction being measured by the commitment to Running Scale based upon the fact the Carmack and Martens (1979) reported that amount run predicted commitment and Sachs (1981) believed amount run also predicted level of addiction. This has also been supported by summers, Machin and Sargent (1983).

The Negative Addiction Scale (see Appendix B) consisted of 24 items. One point was given for answer $1 \mathrm{~A}$; $2 \mathrm{~A}-\mathrm{B}$, and 3B. Items 4 through 12 provided a semantic differential ranging from 1 (strongly agree) to 5 (strongly disagree). One point was given for all "strongly agree" responses for question four through nine and question 11 and 12 . One point was given for a response of "strongly disagree" to question 10. For question 13 one point was given for a response with a 
check. The scoring range was 0-14, higher the score the higher the level of addiction.

\section{Demographic Data}

Age was a necessary demographic component to gather in order that runners could be grouped for analysis in terms of open (age $<40$ years) or masters (age $\geq 40$ years). These are categories in which major competitions cluster competitors. Runners were asked to specify their sex so that runners could be grouped as male or female for comparative analysis.

\section{Selection of subjects}

All subjects included in the study were competitive runners who competed on a regular basis and undertook serious training programs. The study was not concerned with recreational competitive runners or fitness runners. only elite competitive athletes who undertook serious training programs were included. The sample was drawn from two population sources. All member of a TAC registered, athletic footwear sponsored distance running team in the United states were included in the study. To be supported by an athletic footwear corporation ensures that the athlete is indeed elite since only the top level runners in the United States receive this support. Also included were English speaking athletes living in the 
United States listed in the "Guide to Elite Athletes" (Stewart, 1990) which list athletes from around the world who have run sub 29:30 10K or sub 2:20 marathons within the past two years. Through those two sources only elite athletes were sampled.

Of the 200 runners sampled 143 returned instruments for a response rate of $72 \%$. The respondents were employed in the study as subjects $(N=143)$.

\section{Instructions to subjects}

Quasi-experimental, mail survey research methods were employed in the following manner to achieve the stratified sample which was analyzed. Each potential subject was mailed a "Running Behavior Questionnaire" by first class U. S. Mail. Included were self addressed stamped envelopes for returning the completed instruments to the investigator. All questionnaires were mailed on November 16, 1990. A letter and instructions (see Appendix E) specified that all information provided was confidential and that questionnaires were to be returned in the provided self addressed, stamped envelopes provided. Each subject was requested to return the questionnaire to the investigator by December 5, 1990. All were mailed a postcard followup notice on December 18, 1990 which 
requested that they return the questionnaires as soon as possible (see Appendix F).

Included with the "Running Behavior Questionnaire" was a cover letter containing information concerning the research study and instructions for completion and return of the instruments (see Appendix E). Potential subjects were informed that the instruments were part of a study on the running and training behaviors of competitive distance runners. They were instructed to be honest in their responses and assured that there were no "right or "wrong" answers and that their responses were totally confidential since no identification information was requested.

To avoid any type of demand characteristic or response bias the titles of each instrument employed were deleted when used in the research study. The Negative Addiction scale was simply labeled Part $A$, the Commitment to Running Scale Part $B$, and the Obsessive-Compulsive Scale Part C. Part D consisted of demographic questions. These questions sought to ascertain age and sex.

The four separate parts of the instrument each had separate instructional paragraphs. All four parts were then entitled the "Running Behavior Questionnaire" by the investigator (see Appendix D). In the final makeup each of the four parts were randomly ordered to prevent any 
type of demand characteristic due to item type, language, or order of completion.

The "Running Behavior Questionnaire" was made up of four distinct parts, each labeled only with a capital letter. Individual scale titles were not employed. Part A consisted of the Negative Addiction Scale (Hailey \& Bailey, 1982). Subjects were instructed to circle the response which applied to them most of the time. Items 1 through 3 in part $A$ were simple multiple choice. Items 4 through 12 involved a forced choice Likert scale with 4 being strongly agree; $3=$ mildly agree; $2=\operatorname{mildly}$ disagree; and 1 = strongly disagree. Item 13 consisted of 11 responses. The subjects were instructed to check each response which applied to their running behavior (see Appendix D) .

Part $\mathrm{B}$ consisted of the Feeling About Running Scale which sought to measure commitment to running (Carmack and Martens, 1979). Subjects were instructed to circle the appropriate number on a 5 point likert scale which indicated how they feel most of the time. The scale ran from "strongly disagree" to "strongly agree" (see Appendix D) •

Part $C$ of the Running Behavior Questionnaire consisted of the Obsessive-Compulsive Scale with the actual title being deleted so as to avoid any response 
bias. Subjects were simply asked to respond true or false for each of the twenty-two items as they applied to themselves (see Appendix D).

Part $D$ consisted of demographic questions: Subjects were instructed to fill in the blanks with appropriate information. Subjects were instructed to return their completed questionnaires to the investigator as quickly as possible in the provided self addressed, stamped envelope.

\section{Human Subjects Clearance}

According to the regulations of the University of Virginia and the Health and Physical Education program area within the Curry school of Education, the purposes and procedures of this study were carefully reviewed by the doctoral dissertation committee in order to insure the protection of all human subjects. Following a review by the committee which determined no subject would be exposed to any physical or psychological danger through participation in the study, appropriate clearance was granted.

\section{Treatment of Data}

The first step in any type of analysis was to sum the item scores for Part $A$, the Negative Addiction Scale; Part $B$, the Commitment to Running Scale; and Part $C$, the 
Obsessive-Compulsive scale so as to achieve a total score for each subject on each of the three parts. These scores were to be employed in multiple regression analysis. Items in each of the first three parts were reverse coded where needed in order to achieve the correct total score for each instrument employed in the "Running Behavior Questionnaire."

Subjects were also grouped according to their sex and age (open or masters). As a result subjects were broken into male-female, and open or masters level performance groups.

\section{Data Analysis}

Multiple regression analysis was employed to determine the relationship and predictive influence of running addiction as assessed by the Negative Addiction Scale and running commitment as assessed by the commitment to Running Scale on obsessive-compulsive personality as assessed by the obsessive-Compulsive Scale. The individual runner was the unit of analysis $(N=143)$.

The predictor variables (running addiction and running commitment) were regressed on the criterion variable (obsessive-compulsive personality). This regression was done first for all subjects then for males, females, open and master runners individually. 
Simple correlation coefficients (ㄷs) representing each of the predictor variables with the criterion variables were calculated. Also calculated were the intercorrelations of the predictor variables with each other. $R^{2}$ were calculated to determine the relationship of each predictor variable to the criterion variable. All analyses were done first with all subjects in the sample then with male, female, open and masters sub-samples individually.

In an effort to determine the underlying structure of each instrument employed, a principle component factor analysis followed by varimax rotation was computed individually for the Negative Addiction scale, commitment to Running Scale, and the Obsessive-Compulsive Scale. Following these factor analysis computations all items in each of the three instruments were grouped together and considered as one homogeneous scale with all 48 items being employed in a principle component factor analysis. This was done in an effort to determine if there were underlying factors involved which operated between all three of the instruments.

The above factor analyses were computed for all subjects $(\mathrm{N}=143)$. In the original factor analyses the number of factors to be extracted were not specified. All data were analyzed using an SPSS computer program Factor 
Analysis employing PA2 methods in which diagonal correlation elements are replaced with communality estimates and inferred factors are produced automatically. The principle factors with no interactions were first extracted, and then employing varimax rotation, these factors were rotated orthoginally.

\section{Research Questions}

The following questions guided the design, implementation and analysis of the study.

1. What is the relationship between obsessivecompulsive personality with running addiction and running commitment? Do measures of running addiction and running commitment accurately share variance with a measure of obsessive-compulsive personality? Is this true for runners in general and when runners are grouped according to sex and age?

2. Is there one underlying factor in operation between running addiction, running commitment, and obsessive-compulsive personality in runners?

\section{Hypotheses}

The following null hypotheses were tested $(p=<.05)$. HO: There will be no statistically significant shared variance between runner scores of obsessive- 
compulsive personality with running addiction and running commitment in male, female, open or masters runners and runners considered as a whole.

HO: There will be no statistically significant principle component factor in operation between items on the measures of running addiction, running commitment, and obsessive-compulsive personality in elite runners. 
CHAPTER IV

RESULTS

The purpose of this chapter is to present the results of the analyses conducted to determine the characteristics of the subjects; the descriptive statistics and estimates of reliability of the Negative Addiction Scale (Hailey \& Bailey, 1982), the Commitment to Running Scale (Carmack \& martens, 1979) and the Obsessive-Compulsive Scale (Gibb, Baily, Best and Lambirth, 1983); and the predictive influence of scores on running addiction and running commitment on a measure of obsessive-compulsive personality. Also included in the analysis was a rotated factor analysis which sought to determine the clustering of individual items from each of the three scales.

This chapter has four sections. The first section includes demographic data regarding the characteristics of the respondents and descriptive statistics for data on each of three scales employed. The results of the analyses conducted to investigate the predictive influence of running addiction and running commitment on obsessive-compulsive personality are in the second section. The third section presents results of the rotated factor analysis, while the 
final section contains reliability estimates for each scale employed in the study.

\section{Demographic and Descriptive Data}

Two hundred elite distance runners were mailed Running Behavior Questionnaires. Of the 200 mailed, 120 were sent to members of a TAC registered, athletic footwear sponsored competition racing team and 80 were sent to runners listed in the Guide to Prize Money Races and Elite Athletes (Stewart, 1990). Of the 200 questionnaires mailed, 143 were returned for a response rate of $72 \%$. Males accounted for $66 \%$ of the respondents with 95 of 132 males returning questionnaires. Forty-eight of 68 females returned questionnaires which accounted for $34 \%$ of the respondents. In terms of age, open runners (age $\leq 39$ years) accounted for $80 \%$ of the returned questionnaires with 115 . Masters runners (age $\geq 40$ years) accounted for the other $20 \%$ with 28 questionnaires returned.

Because every runner did not respond to every question the $\underline{n}$ could vary from analysis to analysis. In each analysis only the data of those runners who completed all items pertinent to the specific question being analyzed, were used in the computations.

The Running Behavior Questionnaire was made up of three separate scales. The Negative Addiction Scale measured 
running addiction, the commitment to Running scale measured running commitment and the obsessive-Compulsive Scale measured obsessive-compulsive personality. Each of these scales were summed for a total score for each subject. Those scale scores were used in the future analyses. The Negative Addiction Scale had a minimum possible score of 0 with a maximum possible score of 14 . Its mean score in the study was 8.70 with a variance of 3.80 and a range of 9 . The Running Commitment scale had a minimum possible score of 12 and maximum possible of 60 . Its mean score was 49.83 with a variance of 32.95 and a range of 35 . The ObsessiveCompulsive scale had a minimum possible score of 0 with a maximum possible of 20 . Its mean score was found to be 10.80 with a variance of 15.06 and a range of 18 . These descriptive statistics are summarized in Table 1.

Insert Table 1 here

The Predictive Influence of Running Addiction and Running Commitment on Obsessive-Compulsive Personality

This section presents the results of the regression of the predictor variables (running addiction and running commitment) on the criterion variable obsessive-compulsive personality. Regressions are presented for all runners and 
Table 1

Means, Variances, standard Deviations and Ranges for Scores on the Negative Addiction Scale, Running commitment scale and the obsessive-compulsive Personality scale

\begin{tabular}{lccc}
\hline & Mean & Variance & Standard Deviation Range \\
\hline Negative Addiction Scale & 8.70 & 31.80 & 1.95 \\
Commitment to Running Scale & 49.83 & 32.95 & 5.74 \\
Obsessive-Compulsive Scale & 10.80 & 15.06 & 35 \\
\hline
\end{tabular}


then for runners grouped by age $(\leq 39$ years $=$ open, $\geq 40$ years $=$ masters ) and by sex.

Multiple Regression Employing All Subjects

Multiple regression analysis was used to determine the predictive influence of Running Addiction and Running Commitment on Obsessive-Compulsive Personality. Scores on the Commitment to Running Scale and the Negative Addiction Scale were regressed as a set on the criterion variable which was scores on the Obsessive-Compulsive Questionnaire. Intercorrelations were first computed between each of the scale scores. Scores on Negative (Running) Addiction were significantly correlated $(r=.242, \underline{p}<.01)$ with scores on Running Commitment. Scores on Obsessive-Compulsive Personality were not significantly correlated with scores on Negative (Running) Addiction ( $r=.089)$ or Running Commitment $(r=-.030)$ (See Table 2).

Insert Table 2 here

Scores on the Negative Addiction Scale and the Commitment to Running scale were regressed on the criterion variable, Obsessive-Compulsive Personality scores, and the squared multiple correlations were computed. Scores on the Negative (Running) Addiction Scale and the Running Commitment scale did not explain a significant amount of the 
Table 2

Intercorrelations Between Negative (Running) Addiction, Running Commitment and obsessiveCompulsive Personality

\begin{tabular}{lcc}
\hline & RA & RC \\
\hline Running Addiction (RA) & -- & $.242 *$ \\
Running Commitment (RC) & $.242 *$ & $(129)$ \\
$\begin{array}{l}\text { Obsessive-Compulsive } \\
\text { Personality (OC) }\end{array}$ & $(129)$ & -.030 \\
\end{tabular}

$* \underline{p}<.01$

$(\quad)=$ of 143 subjects, number who completed all items pertinent to this analysis. 
variance in scores on Obsessive-Compulsive Personality (See Table 3).

Insert Table 3 here

\section{Multiple Regression: Male-Female Split}

For female runners intercorrelations were first computed between each of the questionnaire scores employed. Scores on the Negative (Running) Addiction Scale were significantly correlated with scores on the commitment to Running Scale $(r=.292, \underline{p}<.05)$ and the Obsessive-Compulsive Scale $(r=.247, p<.05)$. Scores on the Running Commitment Scale were not significantly correlated with scores on the Obsessive-Compulsive Scale (See Table 4).

\section{Insert Table 4 here}

Scores on the Negative (Running) Addiction Scale and the Commitment to Running scale were then regressed on the criterion variable, Obsessive-Compulsive Personality, and the squared multiple correlations were computed. Scores on the Negative (Running) Addiction Scale and the Commitment to Running Scale did not explain a significant amount of the variance in scores on Obsessive-Compulsive Personality in Females (See Table 5). 
Table 3

Multiple Regression of Negative (Running) Addiction and Running Commitment on obsessiveCompulsive Personality

\begin{tabular}{|c|c|c|c|c|c|}
\hline \multirow[b]{2}{*}{ Variable set } & \multicolumn{5}{|c|}{ Obsessive-Compulsive Personality } \\
\hline & $\mathrm{N}$ & $\mathrm{R}$ & $\mathrm{R}^{2}$ & $\operatorname{adj} R^{2}$ & $\mathrm{~F}$ \\
\hline \multicolumn{6}{|l|}{ Running commitment } \\
\hline Negative (Running) Addiction & 143 & .103 & .010 & -.003 & .757 \\
\hline
\end{tabular}


Table 4

Intercorrelations Between Negative (Running) Addiction, Running Commitment, and obsessiveCompulsive Personality in Females

\section{RA}

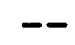

Running Addiction (RA)

Running commitment (RC)

$.292 *$

(43)

Obsessive-Compulsive

Personality (OC)

$.247 *$
$\mathrm{RC}$

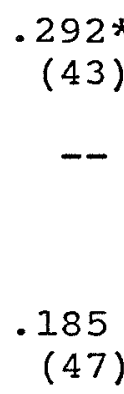

.185 (44)

OC

$-$

$* \mathrm{p}<.05$

$(\quad)=$ of 48 runners, the number who completed all items pertinent to this analysis. 


\section{Insert Table 5 here}

Intercorrelations were then computed for males between each of the questionnaire scores employed. Scores on the Negative (Running) Addiction Scale were significantly correlated with scores on the Commitment to Running Scale $(x=.206, \underline{p}<.05)$. Scores on Obsessive-Compulsive Personality were not significantly correlated with Negative (Running) Addiction scores $(r=.023)$ or Commitment to Running scores $(r=-.163)$ (See Table 6).

Insert Table 6 here

Scores for males on the Negative (Running) Addiction Scale and the Commitment to Running scale were then regressed on the criterion variable, Obsessive-Compulsive Personality scores, and the squared multiple correlations were computed. Scores on the Negative (Running) Addiction Scale and the Commitment to Running Scale did not explain a significant amount of the variance in scores on ObsessiveCompulsive Personality in males (See Table 7).

Insert Table 7 here 


\section{Table 5}

Multiple Regression of Negative (Running) Addiction and Running Commitment on ObsessiveCompulsive Personality in Females

\begin{tabular}{|c|c|c|c|c|c|}
\hline \multirow[b]{2}{*}{ Variable set } & \multicolumn{5}{|c|}{ Obsessive-Compulsive Personality } \\
\hline & $\mathrm{N}$ & $\mathrm{R}$ & $\mathrm{R}^{2}$ & $\operatorname{adj} R^{2}$ & $\mathrm{~F}$ \\
\hline \multicolumn{6}{|l|}{ Running Commitment } \\
\hline Negative (Running) Addiction & 48 & .273 & .074 & .033 & 1.81 \\
\hline
\end{tabular}


Table 6

Intercorrelations Between Negative (Running) Addiction, Running Commitment and ObsessiveCompulsive Personality in Males

\begin{tabular}{|c|c|c|c|}
\hline & RA & $\mathrm{RC}$ & OC \\
\hline Running Addiction (RA) & -- & $\begin{array}{c}206 * \\
(86)\end{array}$ & $\begin{array}{l}.023 \\
(90)\end{array}$ \\
\hline Running Commitment ( $R C$ ) & $\begin{array}{r}206 * \\
(86)\end{array}$ & -- & $\begin{array}{r}-.163 \\
(91)\end{array}$ \\
\hline $\begin{array}{l}\text { Obsessive-Compulsive } \\
\text { Personality (OC) }\end{array}$ & $\begin{array}{c}.023 \\
(90)\end{array}$ & $\begin{array}{r}-.163 \\
(91)\end{array}$ & -- \\
\hline
\end{tabular}

$* \underline{p}<.05$

$(\quad)=$ of 95 runners, the number who completed all items pertinent to this analysis. 
Table 7

Multiple Regression of Negative (Running) Addiction and Running Commitment on obsessiveCompulsive Personality in Males

\begin{tabular}{|c|c|c|c|c|c|}
\hline \multirow[b]{2}{*}{ Variable set } & \multicolumn{5}{|c|}{ Obsessive-Compulsive Personality } \\
\hline & $\mathrm{N}$ & $\mathrm{R}$ & $\mathrm{R}^{2}$ & $\operatorname{adj} R^{2}$ & $\mathrm{~F}$ \\
\hline \multicolumn{6}{|l|}{ Running Commitment } \\
\hline Negative (Running) Addiction & 95 & .172 & .029 & .008 & 1.41 \\
\hline
\end{tabular}


Multiple Regression: Open-Masters split

For open runners, intercorrelations were first computed between each of the questionnaires employed. Scores on the Negative (Running) Addiction Scale were significantly correlated with scores on the Commitment to Running Scale $(r=.278, p<.001)$. Scores on the Obsessive-Compulsive Personality Scale were not significantly correlated with Negative Addiction $(r=.140)$ scores and Commitment to Running scores $(r=-.007)$ (See Table 8$)$.

Insert Table 8 here

Scores on the Negative (Running) Addiction Scale and the Commitment to Running Scale were then regressed on the criterion variable, Obsessive-Compulsive Personality scores and the squared multiple correlations were computed. Scores on the Negative (Running) Addiction Scale and the Commitment to Running Scale did not explain a significant amount of the variance in scores on Obsessive-Compulsive Personality in open runners (See Table 9).

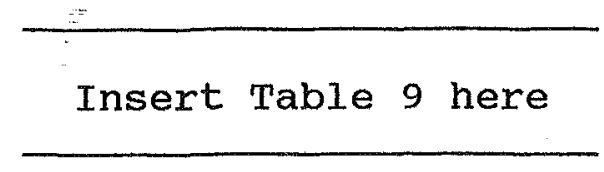

Intercorrelations were then computed for runners 40 years of age and over which are categorized in running as 
Table 8

Intercorrelations Between Negative (Running) Addiction, Running Commitment and obsessiveCompulsive Personality in open Runners

\begin{tabular}{|c|c|c|c|}
\hline & $R A$ & $\mathrm{RC}$ & $O C$ \\
\hline Running Addiction (RA) & -- & $\begin{array}{l}278 * \\
(104)\end{array}$ & $\begin{array}{l}140 \\
(107)\end{array}$ \\
\hline Running commitment ( $R C$ ) & $\begin{array}{l}.278 * \\
(104)\end{array}$ & -- & $\begin{array}{r}-.007 \\
(112)\end{array}$ \\
\hline $\begin{array}{l}\text { Obsessive-Compulsive } \\
\text { Personality (OC) }\end{array}$ & $\begin{array}{l}.140 \\
(107)\end{array}$ & $\begin{array}{r}-.007 \\
(112)\end{array}$ & -- \\
\hline
\end{tabular}

$* \underline{p}<.001$

$(\quad)=$ of 115 runners, the number who completed all items pertinent to this analysis. 


\section{Table 9}

Multiple Regression of Neqative (Running) Addiction and Running Commitment on obsessiveCompulsive Personality in open Runners

\begin{tabular}{|c|c|c|c|c|c|c|}
\hline \multirow{2}{*}{\multicolumn{2}{|c|}{ Variable set }} & \multicolumn{5}{|c|}{ Obsessive-compulsive Personality } \\
\hline & & $\mathrm{N}$ & $\mathrm{R}$ & $\mathrm{R}^{2}$ & $\operatorname{adj} R^{2}$ & $\mathrm{~F}$ \\
\hline Running Commitment & & & & & & \\
\hline Negative (Running) & Addiction & 115 & .147 & .021 & .004 & 1.25 \\
\hline
\end{tabular}


Masters runners. Scores on the Negative (Running) Addiction Scale, the Commitment to Running Scale and the ObsessiveCompulsive Scale were not significantly correlated with each other (See Table 10).

Insert Table 10 here

Scores on the Negative (Running) Addiction Scale and the Commitment to Running Scale were then regressed on the criterion variable, Obsessive-Compulsive Personality scores and the squared multiple correlations were computed. Scores on the Negative (Running) Addiction Scale and the commitment to Running Scale did not explain a significant amount of the variance in scores on Obsessive-Compulsive Personality in Masters runners (See Table 11).

Insert Table 11 here

Principle Factors in the Negative (Running) Adaiction, commitment to Running, and obsessive-compulsive Personality scales

This section presents the results of factor analyses used to determine the underlying structure of the items in the three scales which made up the Running Behavior Questionnaire. Principle component factor analysis followed by varimax rotation for all items from the Negative 
Table 10

Intercorrelations Between Negative (Running) Addiction, Running Commitment and obsessiveCompulsive Personality in Masters Runners

\begin{tabular}{|c|c|c|c|}
\hline & $\mathrm{RA}$ & $\mathrm{RC}$ & $O C$ \\
\hline Running Addiction (RA) & -- & $\begin{array}{l}-252 \\
(25)\end{array}$ & $\begin{array}{c}-.146 \\
(27)\end{array}$ \\
\hline Running commitment ( $R C$ ) & $\begin{array}{l}252 \\
(25)\end{array}$ & -- & $\begin{array}{r}-.175 \\
(26)\end{array}$ \\
\hline $\begin{array}{l}\text { Obsessive-Compulsive } \\
\text { Personality (OC) }\end{array}$ & $\begin{array}{c}-.146 \\
(27)\end{array}$ & $\begin{array}{r}-.175 \\
(26)\end{array}$ & -- \\
\hline
\end{tabular}

$(\quad)=$ of 28 runners, the number who completed all items pertinent to this analysis. 
Table 11

Multiple Regression of Negative (Running) Addiction and Running Commitment on obsessiveCompulsive Personality in Masters Runners

Obsessive-Compulsive Personality

Variable set

\begin{tabular}{lllll}
\hline$N$ & $R^{2}$ & $\operatorname{adjR}^{2}$ & $F$ \\
\hline
\end{tabular}

Running Commitment

Negative (Running) Addiction

28

.204

.041

$-.035$

.543 
(Running) Addiction Scale, Commitment to Running Scale and the Obsessive-Compulsive Personality Scale. A total of 46 separate items were placed into the factor analysis. Seventeen independent factors were extracted with eigen values of 1 or greater. Of these 17 principle factors 3 accounted for $34.9 \%$ of the variance.

Through visual analysis and logical inference it was apparent that these three factors were the major factors in which the three scales' 46 items significantly loaded. As a result a separate factor analysis was performed in which only three factors were specified. With three factors specified the loadings were examined in an effort to determine the underlying structure of the items and if any items grouped significantly together in a manner which represented any principle factors which could be labeled (See Table 12).

Insert Table 12 here

Upon examination, items in the first factor which significantly loaded were those items from the commitment to Running Scale. As a result factor 1 was labeled "commitment to running" in accordance with the fact that its significant loadings were almost exclusively from the commitment to Running Scale. 
orthoginally Rotated Factor Matrix for Negative (Running) Addiction Scale, Commitment to Running Scale and obsessive-Compulsive Personality Scale Items

\section{Factor Loadings}

$\begin{array}{ll}\text { FACTOR 1 } & \text { FACTOR 2 } \\ \text { Commitment } & \text { Obsessive } \\ \text { to } & \text { Compulsive } \\ \text { Running } & \end{array}$

\section{Running}

1. I look forward to running. (RC)

2. I have to force myself to run. (RC)

3. Life is so much richer as a result of running. (RC)

4. Running is vitally important to me. (RC)

5. I do not enjoy running. (RC)

6. Running is pleasant. (RC)

7. I would arrange or change my schedule to meet the need to run. (RC)

8. I wish there were a more enjoyable way to stay fit. (RC)

9. I dread the thought of running. (RC)

10. Running is drudgery. (RC)

11. Running is my primary form of recreation. (RA)

12. Running is the high point of my day. (RC)

13. To miss a days run is sheer relief. (RC)

14. If I stopped running my physical health would decline significantly. (RA)

15. Running has influenced by lifestyle. (RA)

16. I run in unfavorable environments. (RA)

$\begin{array}{lrr}.663 * & -.031 & .072 \\ .641 * & .092 & -.060 \\ .585 * & -.082 & .157 \\ .572 * & -.048 & .115 \\ .548 * & .184 & -.113 \\ .536 * & -.009 & -.143 \\ .531 * & .157 & -.077 \\ .531 * & -.229 & .055 \\ .518 * & .166 & -.107 \\ .506 * & -.186 & -.001 \\ .424 * & -.042 & -.059 \\ .423 * & -.036 & .159 \\ .327 * & -.055 & -.017 \\ .277 & .071 & -.087 \\ .249 & -.091 & .037 \\ .166 & .007 & .016 \\ & & \end{array}$


FACTOR 1

Commitment

to

Running
FACTOR 2

Obsessive

Compulsive
FACTOR 3

(Unnamed)

17. I am usually disciplined and run on days that

I don't feel like doing it. (RA)

18. Running is a common topic of conversation with me. (RA)

19. I like to keep a rigid daily routine. (OC)

20. I believe there is a place for everything and everything in its place. (OC)

21. I'd rather do things the same way all the time. (OC)

22. I like to do things differently each time. (OC)

23. I am uneasy about keeping a rigid time schedule. (OC)

24. I don't feel uncomfortable and uneasy when I don't do things my usual way. (OC)

25. I am not obsessed with details. (OC)

26. I seldom keep a daily routine. (OC)

27. I feel compelled to always complete what I'm doing. (OC)

28. I am seldom compelled to do something I don't want to do. (OC)

$\begin{array}{rcc}.155 & -.048 & -.142 \\ .070 & .013 & -.026 \\ .105 & .612 * & .040 \\ .097 & .612 * & -.064 \\ -.101 & .499 * & .168 \\ .062 & .486 * & .136 \\ .074 & .459 * & -.091 \\ .046 & .407 * & .182 \\ -.039 & .334 * & .119 \\ -.047 & .325 * & .097 \\ -.025 & .306 * & .107 \\ .076 & .281 & .192 \longmapsto\end{array}$


Table 12 (continued)

Orthoginally Rotated Factor Matrix for Negative (Running) Addiction Scale, Commitment to Running scale and Obsessive-Compulsive Personality scale Items

Factor Loadings

FACTOR 1

Commitment

to

Running
FACTOR 2

obsessive

Compulsive
FACTOR 3

(Unnamed)

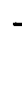

29. I am often compelled to do some things I do not want to do. (OC)

30. I often have recurring thoughts. (OC)

31. If I don't feel like doing something it doesn't bother me not to do it. (OC)

32. I usually never feel the need to be organized. (OC)

33. I seldom have recurring thoughts. (OC)

34. It is important for all runners to take time off from their regularly held running routine. (RA)

35. I experience runners high on the majority of my runs. (RA)

36. I usually check things that I know I have already done. (OC)

37. I seldom check things I know I have already done. (OC)

38. I often feel the need to double check what I do. (OC)

$$
\begin{array}{r}
-.047 \\
-.158 \\
-.119 \\
.055 \\
-.038 \\
-.004 \\
.043 \\
-.070 \\
-.056 \\
-.116
\end{array}
$$

$\begin{array}{rr}.266 & .236 \\ .265 & -.049 \\ .249 & .149 \\ .201 & -.038 \\ .087 & -.071 \\ .078 & -.014 \\ -.061 & -.052 \\ .218 & .664 * \\ .194 & .582 \\ .256 & .580 \stackrel{5}{5}\end{array}$

.236

.149

$-.038$

071

580 N 
Table 12 (continued)

orthoginally Rotated Factor Matrix for Negative (Running) Addiction Scale, Commitment to Running Scale and Obsessive-Compulsive Personality scale Items

Factor Loadings

FACTOR 1

Commitment

to

Running
FACTOR 2

Obsessive

Compulsive
FACTOR 3

(Unnamed)

39. On days I don't run I feel depressed or mentally sluggish. (RA)

40. On days I don't run I feel deprived. (RA)

41. On days I don't run I usually feel guilty. (RA)

42. I feel compelled to do things I don't want to do. (OC)

43. I often do things I don't want to do because I cannot resist doing them. (OC)

44. My interest in running has caused some family and interpersonal tension. (RA)

45. During an average week I run everyday. (RA)

46. Since I have been running my interest and enjoyment in social activities has decreased. (RA)

$\begin{array}{rrr}.117 & -.102 & .408 * \\ .224 & -.054 & .402 * \\ -.085 & -.066 & .353 * \\ -.084 & .281 & .341 * \\ .050 & .133 & .318 * \\ -.113 & .048 & .250 \\ .110 & -.032 & .168 \\ -.087 & .116 & .140\end{array}$

*Significant Factor Loading $\geq .3$

RA=Negative (Running) Addiction Scale $\mathrm{CR}=$ Commitment to Running scale

OC=Obsessive-Compulsive Personality scale 
Factor 2 was loaded most heavily with significant loadings from items which occurred on the obsessiveCompulsive Scale. Nine items from the Obsessive-Compulsive Scale had loadings over .3. These items were ones which dealt with routines and doing things the same way each time. As a result the second factor was labeled "ObsessiveCompulsive."

The final factor contained items which loaded significantly from the Obsessive-Compulsive Scale which dealt with checking and doing things which one doesn't want to do, and also items form the Negative (Running) Addiction Scale which dealt with feelings when a run is missed. No logical grouping of significant factor loadings could be ascertained, and as a result the factor was unnamed. It is worth noting that only three items from the Negative (Running) Addiction Scale loaded significantly in any of the factors (See Table 12).

\section{Reliability of the scales}

This final section presents the results of reliability calculations for the Negative Addiction Scale, Commitment to Running Scale and the Obsessive-Compulsive Scale. Alpha coefficients were calculated using the Kuder-Richardson formula 20. The results are summarized in Table 13. 
Insert Table 13 here

\section{Summary and Conclusions}

This research examined the relationship of the variables running addiction, running commitment and obsessive-compulsive personality as measured by the Negative (Running) Addiction Scale, Commitment to Running Scale and the Obsessive-Compulsive Scale respectively. Multiple regression was performed to determine the predictive ability of running addiction and running commitment on a criterion which was obsessive-compulsive personality. Factor analysis was also performed in an effort to determine the underlying structure of the 46 items of the three scales employed. Reliability coefficients were also calculated.

Data analysis revealed small, yet significant correlations between Running Addiction and Running Commitment in the total sample as well as when the sample was split by sex and with open runners. ObsessiveCompulsive Personality was not significantly correlated with Running Addiction or Running Commitment in any group except for females where Obsessive-Compulsive Personality did significantly correlate with Running Addiction.

Multiple regression analysis of Running Addiction and Running Commitment on Obsessive-Compulsive Personality 
Table 13

Reliability Measures of the Negative (Running) Addiction Scale, Commitment to Running Scale and the Obsessive-Compulsive Scale

$\mathrm{N}$ of items

$$
r
$$

Negative Addiction Scale

14

12

20
.429

.826

.762 
revealed no significant values which would indicate Running Addiction and running commitment explained a significant amount of the variance in Obsessive-Compulsive Personality. This was true for the sample as a whole with splits based upon sex and open masters categories.

Factor analysis revealed no clear factor clusters upon principle component analysis, yet when three factors were specified two factors were extracted which were clearly heavily loaded in the areas of Running commitment and Obsessive-Compulsive Personality.

\section{Results of Test of Nul1 Hypotheses}

The hypotheses stated in chapter three were tested in the null form at the .05 alpha level. The results of the test of null hypotheses are as follows.

Ho There will be no statistically significant shared variance between runner scores when running addiction and running commitment is regressed on obsessive-compulsive personality in all runners, males, females, open and masters runners. Results of the multiple regression indicated no significant shared variance in all runners $(F=.757, p>.05)$, in females $(F=1.81, p>.05)$, in males $(F=1.41, p>.05)$, in open runners $(F=1.25$, $p>.05)$ or in masters runners $(F=.543, p>.05)$. 
Therefore the null cannot be rejected at the .05 alpha level.

Ho There will be no statistically significant factor in operation between items on the measures of running addiction, running commitment and obsessive-compulsive personality in elite runners. The results from the factor analysis indicated 17 separate principle component factors with eigen values of one or greater yet none loaded logically with any of the items. When three factors were specified analysis resulted in two separate nameable factors. However, one factor was not evident between the three scales. Therefore, the null hypothesis cannot be rejected. 


\section{CHAPTER V}

\section{DISCUSSION}

The purpose of this research was to determine if running addiction and running commitment shared a significant amount of variance with obsessive-compulsive personality. If variance was found to be shared obsessive-compulsive personality is based on the same construct as running addiction and running commitment. The study examined the relationship of the variables running addiction, running commitment and obsessivecompulsive personality as measured by the Negative (Running) Addiction Scale (Hailey \& Bailey, 1982), Commitment to Running Scale (Carmack \& Martens, 1979) and the Obsessive Compulsive Scale (Gibb, Baily, Best \& Lambirth, 1983) respectively.

Elite distance runners from the United States served as subjects for the study $(\mathrm{N}=143)$. Multiple regression was performed to determine the predictive influence of running addiction and running commitment on the criterion variable which was obsessive-compulsive personality. Factor analysis was also performed in an effort to determine the underlying structure of the 46 items of the 
three scales employed. Reliability coefficients were also calculated.

The discussion of the findings will be presented in four major sections. The chapter first discusses the major findings with comparison and contrast with the existing literature and theoretical perspectives of the hypothesized results. The second section provides conclusions and possible differing perspectives as to the bases for the results. The third section deals with limitations of the study. The fourth and final section includes practical implications and suggestions for future research in the area.

\section{Discussion of Major Findings}

A major goal of this research was to examine the potential relationship between what the literature had termed running addiction, running commitment and obsessive-compulsive personality. Initial correlations revealed that the Negative (Running) Addiction Scale, which intended to measure running addiction, and the Commitment to Running scale which intended to measure running commitment did indeed correlate significantly with each other. However, the correlation even though significant was very low $(r=.242, p<.01)$. This result was 
surprising in that from visual examination the two scales appeared to have somewhat identical items (See Figure 6).

Insert Figure 6 here

It could have been expected that the Negative (Running) Addiction scale and the Commitment to Running scale would have correlated much higher since those items were almost identical. In fact, Sachs (1981) has actually employed the commitment to Running scale as a measure of running addiction.

The Negative (Running) Addiction Scale and the Commitment to Running scale did not approach significant correlation with the Obsessive-Compulsive Scale. In fact the Commitment to Running scale actually had a small negative correlation $(-.030, \mathrm{p}>.05)$ with the ObsessiveCompulsive Scale. Again this result was surprising in light of the similarities of the items in each scale as demonstrated in Figure 6.

When the subjects were split and analyzed by sex the females were found to have significant correlations between the scores on running addiction and commitment to running $(r=.292, \underline{p}<.05)$. Obsessive-compulsive scores also significantly correlated with running addiction scores in 
NEGATIVE (RUNNING) ADDICTION SCALE
COMMITMENT TO RUNNING SCALE
OBSESSIVE-COMPULSIVE SCALE

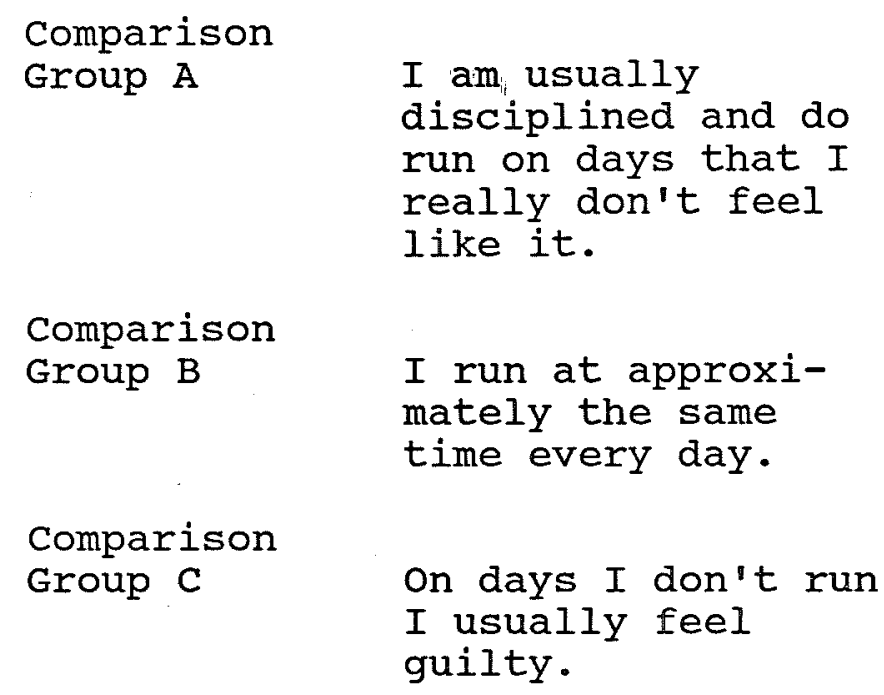

I have to force myself to run.

I would arrange or change my schedule to meet the need to run.

To miss a day's run is sheer relief.*
I feel compelled to do things I don't want to do.

I like to keep a rigid daily routine.

If I don't feel like doing something it doesn't bother me not to do it.*

*Reversed scoring employed

Fiqure 6. Comparison of Selected items from the Negative (Running) Addiction Scale,

Commitment to Running Scale and the Obsessive-Compulsive Scale. 
females $(r=.247, \underline{p}<.05)$. Again, even though the correlations were significant they were unexpectedly low.

For males running addiction scores were significantly correlated with running commitment scores, but the correlation was unexpectedly low $(r=.206, p<.05)$. Scores on the Obsessive-Compulsive Scale were not significantly correlated with running addiction scores or running commitment scores in male subjects.

When the sample was split into open and masters runners categories the same pattern was evident. For open runners, running addiction scores were significantly correlated with running commitment scores but still the correlation was lower than was expected $(r=.278, \underline{p}<.001)$. Obsessive compulsive personality again failed to correlate significantly with running addiction or running commitment in open runners. Masters runners actually presented no significant correlations between any of the three variables under consideration. As mentioned earlier the low and almost non-existent correlations were quite surprising considering the items from all three scales appeared to be so similar.

Multiple regression analysis revealed no significant $\mathrm{R}^{2}$ values when running addiction and running commitment were regressed on the criterion variable, obsessivecompulsive personality. When examining the entire sample 
running addiction and running commitment accounted for only .01\% of the variance in obsessive-compulsive personality. It would certainly appear from this low $\mathrm{R}^{2}$ that the Negative (Running) Addiction Scale, Commitment to Running Scale and the Obsessive-Compulsive Scale are indeed measuring different variables.

When the sample was split by sex, the same results were expected. For females, running addiction and running commitment explained only .07\% of the variance in obsessive-compulsive personality. For males, only .02\% of the variance was accounted for in obsessive-compulsive personality by the two predictor variables. In the present study no differences in the sexes may have been expected based upon Carmack and Martens (1979) who found that in runners who average over 40 miles per week there were no differences in commitment to running scores between males and females. This finding also supported Summers, et al. (1983). On the other hand, Masters and Lambert (1989) reported that females scored higher on the Commitment to Running Scale than males and also had a higher level of perceived addiction. In the present study, no significant differences could be detected between males and females when the predictive ability of 
running addiction and running commitment was tested on the criterion variable, obsessive-compulsive personality.

When looking at open runners as a group, running addiction and running commitment explained only .02\% of the variance in obsessive-compulsive personality. For masters runners, only .05\% of the variance was explained by the predictor variables.

All of these results were not expected based upon similarities of items in the three scales. As stated earlier even though each instrument employed supposedly measured different variables, the items on each scale appeared to be almost exact in their outward appearance. The Commitment to Running Scale (Carmack and Martens, 1979)had actually been used by Sacks and Sachs (1981) to measure running addiction in their research because they couldn't develop a better measurement technique. However in this study the scores on the Negative (Running) Addiction scale did not correlate highly with scores on the Commitment to Running scale. From these results an examination of the reliability and validity of the two instruments would appear to be warranted.

It would be expected that if the Negative (Running) Addiction Scale, Commitment to Running Scale and the Obsessive-Compulsive Scale were all measuring the same variable then their items, when placed into a factor 
analysis should load highly into one main factor. The results indicate this was certainly not the case. In fact 17 factors were extracted with Eigen values of one or greater. Upon examination none of these factors made any logical sense when their loadings were analyzed. Clearly there was more than one variable in operation between the items.

The next logical step was to specify three factors to be extracted based upon the fact that the three scales supposedly measured three different constructs. With three factors specified a very interesting pattern of factor loadings developed. Factor one loaded highly with items from the commitment to Running scale while factor two loaded highly with items from the obsessive-compulsive Scale. However, only two items from the Negative (Running) Addiction Scale exhibited significant loadings in any factor. Again this would lead one to question how valid and effective the Negative (Running) Addiction Scale is as an indirect measuring instrument since it would be expected that the Negative (Running) Addiction Scale would load significantly in one factor if it were indeed valid. Why then, even though the three instruments appeared to be so similar in their item makeup, did they fail to provide any analytical indication that they were measuring the same variable. There are several possible 
explanations for the non-significant results of the multiple regression and factor analysis in the study. First, each instrument could indeed be measuring different variables. If each measure is valid and reliable then it would appear that the Negative (Running) Addiction Scale, Commitment to Running scale and the obsessive-Compulsive Scale are each measuring separate variables.

of the three instruments Carmack and Martens (1979) appear to have developed their commitment to Running scale with more scientific rigor than the others. Concurrent validity was demonstrated by employing groups of questions based upon Glassers (1976) positive addiction concept. Carmack and Martens reported that questions from groups which dealt with length of run, discomfort when a run is missed and perceived addiction to running did indeed predict significantly. Commitment to Running scores indicated substantial concurrent validity. Employing internal consistency assessment the twelve items from the Commitment to Running scale had a mean inter-item correlation coefficient of .30 and when the KuderRichardson 20 was applied a reliability coefficient of .97 was obtained. Employing Kuder-Richardson 20 in the present study, a reliability coefficient of .82 was obtained for the Commitment to Running scale and while this was not as high as Carmack and Martens initial 
measure, it does indicate an acceptable degree of reliability in the study.

It would appear from the factor loadings and reliability estimates that the Commitment to Running Scale was a valid, reliable measure in the present study. This result is in agreement with Masters and Lambert (1989), who also reported the commitment to Running scale exhibited high construct validity in their study on running commitment and gender comparison. Sachs (1981) also obtained a test-retest reliability coefficient of .84 in his work on running addiction employing the commitment to Running Scale as a measuring device.

The Obsessive-Compulsive Scale (Gibb, Bailey, Best and Lambirth, 1983) was developed in a scientific manner, yet, without the rigor of the commitment to Running scale. The twenty-two items of the Obsessive-Compulsive Scale were selected from an original pool of 68 items through factor analysis. The validity of the final twenty-two items was determined by having subjects complete the scale and then be rated on compulsivity and obsessiveness by two clinicians. When the two ratings were correlated a coefficient of $.79(\underline{p}<.0001)$ was found indicating promising construct validity. The authors also reported a test-retest reliability measure of .82 which indicated an acceptable level of reliability. In the present study 
employing the Kuder-Richardson 20 reliability formula a reliability coefficient of .76 was found. From this information it would appear that the obsessive Scale was, at the very minimum, a measuring instrument which exhibited acceptable validity and reliability.

on the other hand the Negative (Running) Addiction Scale would appear not to maintain acceptable levels of validity or reliability. Hailey and Bailey (1982) reported no validity or reliability for the Negative (Running) Addiction scale upon publication and the present study would certainly not indicate acceptable validity or reliability. It could be hypothesized that if the Negative (Running) Addiction Scale was actually a valid measure of running addiction, then, it would have correlated much higher than .24 with the Commitment to Running Scale which does report validity as a measure of running addiction. Also employing the Kuder-Richardson Formula 20 reliability analysis it was found in the present study that the Negative (Running) Addiction Scale had a reliability coefficient of only .42 which would indicate a high degree of error of measurement. This finding coupled with the fact that the Negative (Running) Addiction scale failed to load significantly on any factor when the other two instruments loaded cleanly on 
individual factors would indicate that the reliability and validity of the scale is questionable.

Even the scoring method of the Negative (Running) Addiction scale must be questioned. On the scales 5 point likert items a point could be gained only if a 5 or strongly agree response was provided. This scoring method would seem to limit the variability of the scores, as well as result in the scale being under sensitive to differences in subjects. As an experimental analysis, different methods of scoring were done for the Negative (Running) Addiction Scale, but resulted in no significant changes in the variability of scores. As a result of all the information available it would appear that the validity of the Negative (Running) Addiction Scale as an effective measure is questionable.

Based upon the knowledge of the validity and reliability of each scale one could hypothesize that the Obsessive-Compulsive Scale and the Commitment to Running Scale are actually measuring different construct variables. However, it would be difficult to make the assumption that the Negative (Running) Addiction Scale actually measured running addiction or any other construct based upon its validity and reliability history.

on the other hand there always remains the possibility that the vague constructs of running addiction 
and obsessive-compulsive personality may not at the present time be able to be effectively measured in any type of quantitative manner with one simple paper-pencil instrument. At the present time, there is still little importance placed upon self-report measures to evaluate obsessive-compulsive disorders. Because of the problems of differential diagnosis, clinical symptoms are still employed as the primary form of assessment (Hoogduin, 1986).

Because compulsivity and obsessiveness are vaguely defined terms which include a broad range of behaviors and cognitions they are very difficult to quantify (Gibb, Bailey, Best \& Lambirth, 1983). One could argue that this is true for such vague terms as dedication, commitment, and running addiction as well. As Philpott (1975) reported, these vague terms have multiple wide ranges of meanings, symptoms and sometimes disabilities. These therefore tend to render questionnaires unreliable as well as providing individual measures which are unreliable between subjects or studies. Certainly more refinement needs to be done on the paper-pencil instruments with the possible addition of open ended interview methods which intend to measure compulsivity and obsessiveness if paperpencil instruments are to be used as a means for accurate evaluation. The possibility does indeed exist that some 
runners in the present study did indeed suffer from an obsessive-compulsive disorder, but because of the difficulty in measurement the scores on the obsessiveCompulsive may not indicate it. Even though no literature is available on the subject we could certainly theorize that an individual could have obsessional type thoughts about running and only be able to reduce these thoughts through actually going out and running. Possibly as we continue to examine and harbor knowledge about obsessivecompulsive disorders we will see that many exercise and leisure activities are obsessive-compulsive behavior outlets for many individuals.

In terms of running addiction the same measurement problems obviously exist. Since exercise addiction is a very new area of study which was only first examined by Baekland in 1970, there has been a limited amount of research done in the area. As a result of the limited and confused research in the area, the question must be asked if there really is any construct which could be labeled running addiction or is it a catch all term which has been popularized in magazines. As Carnes (1983) has suggested, addiction may be a classic instance of moral judgement parading around as a scientific fact. According to Wedin (1984) an addiction can only exist when a state of physiological dependence results from habitual use of a 
specific substance. Hoogduin (1986) also says that an addiction results when a person repeatedly uses external substances to bring about changes in his or her psychological state. Similarities can be observed between running addiction and what Schwartz and Brasted (1985) have termed "sexual addiction." Both of these so-called addictions are the only ones in which the addict is not expected to give up his or her "drug" of choice as part of the treatment. In fact the World Health Organization in Geneva doesn't even recognize the word addiction (Worick \& Schaller, 1977) instead favoring the term dependence.

Based upon the findings of the study the question must be raised if running addiction really exists as a construct. Each scale employed in the study demonstrated questionable levels of validity and reliability and it could possibly be hypothesized that the reason for this is the constructs of running addiction, or as carmack and Martens (1979) have termed it, commitment to running may not be in existence and therefore be impossible to measure. Whatever the three scales measured the results would indicate that there are three things being measured, but how can we be sure what they are? Just because a scale has a name does not mean that the scale measures what it says it measures. 
If running addiction does not exist then what are the implications? Certainly there is some type of desire, dedication, etc. which leads to a regular pattern of running and in the future it would be more important to examine why people run, if the running is a positive or negative for them, and ways to maximize effective running behavior, instead of trying to label behavior with titles drawn from other areas of science and psychology. The constructs of addiction, commitment and obsessivecompulsive may indeed exist, but they may exist in every part of the general population. The literature, as demonstrated in chapter II presents much evidence of obsessive-compulsive and addictive problems in our society, but can researchers take terms like these and simply force them to fit specific behaviors and activities? Great caution must be employed when taking terms from one area of study and simply applying them to another without sound scientific support. It is very easy to apply labels, but do these labels fit? This question must be raised when discussing addiction and obsessivecompulsive complaints and running.

The term addiction is so common in today's society that it is often used without consideration as to its true meaning. In many instances it would appear that being addicted to something is almost a necessity in our 
society. It would appear that if an individual claims to be addicted to their activity it's a source of pride over being really involved and "into" something. It would seem to be the case that the perception of being addicted to running has become part of the runners self concept and it's almost expected of those who are serious about running (Carmack \& Martens, 1979). From what is written it would appear that athletes can no longer be dedicated. If they work hard at their sport they're considered to be addicted.

So much has been written recently in the popular literature on running addiction that it is possible that some type of demand characteristic or social desirability factor could be in operation when runners answer any type of question related to running. Robbins and Joseph (1980) have suggested that certain symptoms may be frequently reported because articles on exercise addiction in popular literature lead runners to believe they should experience certain things when they run or don't run. Robbins and Joseph (1980) have termed this the "Runners World" effect. When responding to running related items the social desirability of being addicted could possibly come into play in both directions. Some runners may want to appear addicted while others may do anything to appear not being addicted. 
Social desirability may also be in operation in the opposite direction when answering obsessive-compulsive items for certain individuals. They may not want to appear that they are "abnormal" in that they"feel compelled to do something they don't want to do" or perform certain ritualized behaviors. As a result they may respond in a manner which protects them from socially undesirable responses on paper-pencil instruments which are intended to measure obsessive-compulsive complaints. clinical interviews may well be the only way to accurately get at an individual's psychological perspective on running or their level of compulsivity or obsessiveness. certainly demand characteristics and social desirability must be considered when interpreting the results of the present study. As Sachs (1981) points out runners tend to be well educated. Many runners are introspective enough to see through many types of measurement techniques.

Another possible factor in the nonsignificant results has to do with the sample employed in the study. Each scale had specific inherent problems simply by the nature of the populations used in their development. First, the Negative (Running) Addiction Scale and the Commitment to Running scale were both developed using runners of all ability levels from world class athletes all the way down to once a week joggers as well as sexes being considered 
together. All participants in the developmental stages of the Negative (Running) Addiction scale and the commitment to Running were simply volunteers at local races and even college physical education classes. The norms developed from these samples may not compare favorably with the sample which was employed in the present study. It may be hypothesized that the elite distance runners sampled in the present study would have a very different outlook on running and training than would a recreational runner or physical education student. When speaking of "getting in shape", for an elite runner this means years, even a decade, not weeks or days, of carefully planned training so as to develop their genetic potential. Just because an athlete works hard does not mean they have to be labeled addicted. For comparison few people would say an individual in the business world who works overtime is addicted. Most persons would call him or her a model employee.

However it must be pointed out that simply being committed does not in any way guarantee high levels of performance. Even though the Commitment to Running Scale appears to be a useful measuring instrument, there is no evidence that it can be employed as a predictor of performance and the authors do not claim this. One main reason for this is the fact that high scores on the 
Commitment to Running scale have no bearing on the quality of workouts. Just because an individual is committed and runs everyday does not mean they are running hard, quality-type workouts which are needed to stress the body to produce higher levels of performance. High levels of commitment to running do not necessarily indicate high levels of commitment to performance. An individual can be committed to running without being committed to run fast races.

What is "commitment" for one runner may not be "commitment"for another. Some individuals may think running three times a week is extremely committed while another runner may feel running three times a week is a total lack of commitment. There can be commitment to running without commitment to success in competitive running. There is a major difference between training to race and simply running everyday. In a training program a runner must endure pain and discomfort which comes with intense workouts if they expect to improve their race day performance. On the other hand many runners who run for pleasure may actually avoid pain at all costs. Both may be committed, yet each runner has a different outlook on what they expect from their running. Commitment can in no way always be linked with successful performance. 
It could also be theorized that the more one is committed to running the more time or distance they would actually run. Carmack and Martens (1979) actually report that length of run is a valid predictor of commitment to running scores. Masters and Lambert (1989) have reported, especially in males, that the higher the score on the Commitment to Running scale the more mileage run. This would lead us to pose the question that if this relationship is indeed true then why can we not simply gather data on how a person runs instead of having them fill out a Commitment to Running Scale? Mileage per week may indeed be a very valid predictor of how committed one is to running.

Care must be taken in interpreting and generalizing the results of the present study because of the influence of the sample. The elite runner should not be placed into an all encompassing category of "runners." The findings from elite runners should not be expected to generalize to runners in general. Many people run for fun, fitness, social reasons, weight reduction, and a variety of other motives. Therefore, care must be taken when runners are compared in terms of their competitive outlooks on the sport. The sport of running is unique in that a "fan" can actually register and participate right along with the "pro". Certainly not all of the 25,000 runners in the New 
York City Marathon are trying to win the race, win prize money or run a time which will place them on the world Iist. Each individual has different motivations and goals for which they strive. It doesn't make logical sense to study all as one. If one were to study the psychological perspectives of "pro" baseball players certain subjects would not be obtained by driving through the country side and stopping at every backyard or sandlot game to gather data.

In summary care must be taken when developing indirect self-report measurement instruments and in generalizing the findings to specific populations. Even the Obsessive-compulsive scale has certain limitations to its generalizability and use with certain populations. The Obsessive-Compulsive Scale was developed using students from a college psychology class. Can it be safely said that this scale would have been developed with the same outcome if hospitalized patients with obsessiveCompulsive complaints were used or if the development used athletes? Probably not, and as a result, sport psychology professionals must use the utmost caution when employing paper-pencil instruments as information gathering and diagnostic tools which will guide their counseling of athletes. The instruments employed in the present study would certainly not in and of themselves be appropriate 
for assessing a runners psychological makeup and their perceived needs of performance or health counseling especially considering the validity and reliablity questions concerning their power.

As Sachs (1981) has pointed out sport psychologists and coaches must be aware of the implicit moral judgment which is made when the term addicted is used, or for that matter, obsessive-compulsive. If an individual is labeled as addicted to running is this necessarily bad? Maybe they are just committed to high levels of performance or good health. Many runners are educated and introspective enough to know that even though their lives are dominated by running, it still may indeed be positive (Waters, 1981).

of course the outcomes of running must be examined as well in order to accurately examine the positive and negative aspects of the activity. If a runner is a successful competitor on the world class level, yet he hates to run, but likes the feeling of winning, then is running a negative for him? The joy and happiness a runner receives intrinsically from a good race performance may be well worth the negative aspects of hard training. However, if a runner's exercise behavior is seriously damaging their health then we may possibly have reason to determine that their running behavior is a negative aspect 
of their lives. Hopefully, most runners have the proper perspective and realize when serious harm is being done to their bodies, and as a result, back off. However, sport psychology professionals must differentiate what is healthy or non-healthy and what is helping or hindering performance. With this in mind negative aspects of running can be considered from a motivational perspective. If a runner is motivated by fear and guilt, and as a result, is always miserable then one could possibly argue this to be a negative need to run. On the other hand if an individual runs because they love to run and it brings them feelings of positive emotion should one possibly judge this to be negative as well. The differences between positive and negative motivations for running and other exercise needs to be clarified.

Two of the scales employed in the study attempted in an indirect manner to get at the positive and negative aspects of so-called running addiction, yet because of the similarity of the items, what is positive or negative is difficult, if not impossible, to sort out without making some type of moral jüdgment. The Negative (Running) Addiction scale attempted to examine running addiction from the negative point of view, yet its' items were so similar to the Commitment of Running Scale, which was developed based upon Glassers (1976) idea of positive 
addiction, that differentiating between negative and positive on either scale appears to be a non-empirical matter of personal opinion. This coupled with the low reliability and validity of the Negative (Running) Addiction Scale would make it extremely difficult to draw any type of conclusion based upon its measures.

In terms of positive and negative motivations we could possibly draw the conclusion from the literature that a person may not be considered obsessive-compulsive if they derive pleasure from their running. This is based on the DSM-III (APA, 1980) which points out that activities such as running cannot be considered true "compulsions" because the person may derive true pleasure from running and may wish to avoid running only because of its negative secondary consequences. However, if a person is negatively motivated by fear, guilt or anxiety which results from the thought of not running, and the only way these fears and anxiety are reduced is through running, it could possibly be concluded that the individual may suffer from a running specific obsessive-compulsive disorder. Certainly it would be very important to the sport psychologist to be able to differentiate between runners who run because they love to run and those who run simply because they have high levels of anxiety if they don't. There would appear to be a major difference between those 
who run for the pleasure of the act and those who run for the relief of anxiety which results from not running. This difference would results in differing perspectives in counseling in a situation in which sport psychologists attempt to help an individual in terms of health, happiness and performance. clearly much is still to be learned concerning the psychology of running and exercise and ways to effectively use this knowledge to help facilitate happier, healthier, and faster runners.

\section{Conclusions}

The purpose of this study was to investigate the relationship between running addiction, running commitment, and obsessive-compulsive personality as measured by the Negative (Running) Addiction Scale, Commitment to Running scale and the obsessive-Compulsive Scale respectively. Multiple regression analysis was employed to determine the predictive influence of running addiction and running commitment on the criterion variable, obsessive-compulsive personality. The analysis was done employing 143 elite distance runners as subjects. Analyses were also performed as well in an effort to determine the underlying structure of the 46 items included in the three instruments employed. 
The results from this study supported the following conclusions and practical implications:

1. In elite runners, it would appear that the variable constructs running addiction, running commitment and obsessive-compulsive personality are separate constructs. This result is also true when the sample was split according to sex and age (open vs masters).

2. The Commitment to Running Scale and the Obsessive-Compulsive Personality Scale are measuring instruments which measure two separate constructs. However, the constructs may not actually be commitment or obsessive-compulsive personality based upon the validity of the instruments.

3. The use of the Negative (Running) Addiction Scale as an acceptable measuring device is questionable in light of its lack of demonstrated validity and reliability and its lack of significant loading in factor analysis.

4. Running Addiction and Running Commitment are not significant predictors of obsessive-compulsive personality in elite runners or when the elite runners are examined based on sex and age (open vs masters).

5. Better measurement techniques need to be developed in order to effectively study running addiction. Finally it is apparent from the findings of this investigation that the assessment techniques employed by 
sport psychology professionals are of the utmost importance. Without valid, useful means for assessment of athlete concerns, the sport psychologist cannot expect to provide an effective level of assistance. Even though this study has added new data concerning the psychological involvement in running and its effective measurement, much more research must be done in the area before running and other exercise behaviors can be effectively understood. This study clearly raises many new questions. Suggestions for additional research appear later in this chapter.

\section{Limitations}

The conclusions and implications of the present study are subject to the following limitations:

1. The sample employed for this study was limited to elite distance runners. The degree to which results of this study generalize to other runners is unknown. Also because the instruments were not developed based upon sex or age differences the generalizability to sub-groups must be questioned. Low number of subjects in the female $(\mathrm{N}=48)$ and masters ( $\mathrm{N}=28)$ groupings may have impacted the results of the split groupings.

2. The Negative (Running) Addiction Scale employed in the study had low levels of validity and reliability. 
3. The Negative (Running) Addiction Scale employed a limited range method of scoring.

4. Data obtained in the study depended upon the perceptions of the runners sampled. The accuracy of the data was dependent on the ability of the runners to respond honestly to the items.

5. There was limited control over situational variables and respondent characteristic variables. The degree to which these variables influenced the results is unknown .

6. Because there was no type of experimental control and the analysis was correlational causal conclusions are not possible.

\section{Recommendations for Future Research}

This section presents the implications for future research suggested by the design and implementation of this study. It is recommended that:

1. paper-pencil type scales which are intended to measure variables such as addiction, commitment, etc. be developed employing rigorous scientific methods as have scales in the field of psychology such as the MMPI. If the field of sport of Psychology is to continue to gain acceptance it must be subject to the same stringent 
psycho-socio scientific standards as other behavioral sciences.

2. researchers use open ended interview research methods in concordance with paper-pencil scales when attempting to more accurately ascertain levels of psychological involvement of runners with their sport.

3. continued refinement be stressed in the development of Obsessive-Compulsive measurement instruments

4. norms be established for Obsessive-Compulsive runners.

5. elite runners be compared with runners of different physical ability levels and psychological involvement levels.

6. researchers attempt to develop a set of traits which will help predict a profile of those runners who will develop dysfunctional excessive running behavior patterns, whether they be "addicted" or obsessivecompulsive.

7. early childhood and adolescent experiences be examined in an effort to better learn how dysfunctional exercise behavior develops.

8. additional sport specific athlete "addictions" be identified and investigated. 
9. in-depth case study research be conducted into the psychological makeup of elite endurance athletes.

10. a running specific Obsessive-Compulsive scale be developed.

11. this study be replicated with other runner performance levels.

12. further research be done between male and female runners on their psychological perspectives on running.

13. further psycho-biological research be conducted on runners to determine more conclusively the relationship of endogenous opiods and any addiction.

14. coaching behaviors be examined in an effort to better understand dysfunctional running behaviors and to avoid further contributions to the behaviors.

15. running addiction be examined through a multidimensional model rather than a unidimensional model as Sachs and Pargman (1979) have suggested.

16. motivations for running be examined with more of an emphasis on the positive and/or negative aspects of the motives.

17. effective running behaviors be determined for successful competitive runners. 
REFERENCES

Abe11, R. (1975). Confessions of a compulsive. Runners World, $10,30-31$.

Adler, A. (1927). Understanding human nature. Garden City, NY: Greenberg Press.

Allen, J.J., \& Tune, G.S. (1975). The Lynfield obsessional-compulsive questionnaire. Scottish Medical Journal, 20, 21-26.

American Psychological Association. (1980). Diagnostic and statistics manual of mental disorders ( 3 rd ed.). Washington, D.C.: American Psychological Association.

Baekeland, F. (1970). Exercise deprivation: Sleep and psychological reactions. Archives of General Psychology, 22, 365-369.

Beck, A.R. (1976). Cognitive therapy and emotional disorders. New York: International Universities Press.

Bradman, K., Deutschenberger, J., \& Wolff, H.G. (1956). Manual for the Cornel1 Medical Index Health Questionnaire. New York: Cornell University Medical college.

Burns, D.D. (1980). Feeling good: The new mood therapy. New York: Marrow.

Burns, D.D., \& Beck, A.R. (1978). Cognitive behavior modification of mood disorders. In J. P. Foreyt and D.P. Rathjen (Eds.). Cognitive Behavior Therapy: Research and Application. New York: Plenum.

Buros, O.K. (1974). Test in print. Highland Park, NJ: Gryphon Press.

Caine, T.M., \& Hawkins, L.G. (1963). Questionnaire measure of the hysteroid/obsessoid component of personality. Journal of Consulting Psychology, 27, 206-209.

Caine, T.M., \& Hope, K. (1964). Validation of the Maudsley Personality Inventory E Scale. British Journal of Psychology, 55, 447-452. 
Carmack, M.A., \& Martens, R. (1979). Measuring commitment to running: A survey of runner's attitudes and mental states. Journal of Sport Psychology, 1, 25-42.

Carnes, P. (1983). out of the shadows: Understanding sexual addiction. Minneapolis, MN: Comp Care Publications.

Cattell, R.B., \& Eber, H.W. (1957). Handbook for the sixteen personality factor questionnaire. Champaign, IL: Institute for Personality and Ability Testing.

Cherrington, D.J. (1980). The work ethic. New York: AMACOM, American Management Association.

Chonko, L.B. (1983). Job involvement as obsessioncompulsion: Some preliminary empirical findings. Psychological Reports, 53, 1191-1198.

Cooper, J.E. (1970). The Leyton Obsessional Inventory. Psychological Medicine, 1, 48-64.

Cooper, J.E., \& MCNeil, J. (1968). A study of house proud housewives and their interaction with their children. Journal of Child Psychology and Psychiatry, 9, 173188 .

Coryell, W. (1981). Obsessive-Compulsive disorder and primary unipolar depression. Journal of Nervous \& Mental Disorders, 169, 220-224.

Crossman, J., Jamieson, J., \& Henderson, L. (1987). Responses of competitive athletes to lay-offs in training: Exercise addiction or psychological relief. Journal of Sport Behavior, 100, 28-38.

Deutsch, H. (1965). Neuroses and character types. New York: International University Press.

Dowson, J.H. (1977). The phenomonology of severe obsessive-compulsive neurosis. British Journal of Psychiatry, 131, 75-78.

Ellenberger, H. (1970). The discovery of the unconscious. New York: Basic Books, p. 386.

Eysenck, H.J. (1959). Manual of the Maudsley personality inventory. London: Methuen. 
Farrel1, P.A., Cates, W.K., Maksud, M.G., Morgan, W.P., \& Tseng, L.F. (1981). Plasma beta-endorphinel beta lipotropic immunoreactivity increases after treadmill exercise in man. Medicine and Science in sports and Exercise, 13, 134 .

Flament, M. \& Rapoport, J. (1984). Childhood obsessivecompul'sive disorder. In Insels, T. (ed.), New Findings in Obsessive-Compulsive Disorder. Washington:

American Psychiatric Press.

Foa, E.B., \& Steketee, G.S. (1979). Obsessive-compulsives: conceptual issues and treatment interventions. In Progress in Behavior Modification, Hersen, M. and Eisler, R.M. (Eds.). New York: Academic Press.

Forbes, A.R. (1969). The validity of the 16PF in the discrimination of the hysteroid and obsessional personality. British Journal of Social and Clinical Psychology, 8, 152-159.

Freud, S. (1953). The predisposition to obsessional neurosis. In Freud, S. Collected Papers, Vol. 2. New York: Basic Books.

Gibb, G.D. , Baily, J.R., Best, R.H., \& Lambirth, T.T. (1983). The measurement of the obsessive-compulsive personality. Educational and Psychological Measurement, 43, 1233-1238.

Gittleson, N. (1966). The depressive psychosis in the obsessional neurotic. British Journal of Psychiatry, $112,883-887$.

Glasser, W. (1976). Positive addiction. New York: Harper and Row.

Gontag, A., Clitsome, T., \& Kostrubala, T. (1978). A psychological study' of 50 sub-3-hour marathoners. In Milvey, P. (ed.) The Long Distance Runner: A Definitive Study. New York: Urizen Books.

Goodwin, D., Guze, S., \& Robins, E. (1969). Follow-up studies in obsessional neurosis. Archives of General Psychiatry, 20, 182-187.

Hailey, B.J., \& Bailey, J.A. (1982). Negative addiction in runners: A quantitative approach. Journal of Sport Behavior, $5,150-154$.

Hamachek, D.E. (1978). Psychodynamics of normal and neurotic perfectionism. Psychology, 15, 27-33. 
Harris, M.B. (1981a). Runner's perceptions of the benefits of running. Perceptual and Motor Skills, 52, 153, 154 .

Harris, M.B. (1981b). Women runner's views of running. Perceptual and Motor Skills, 53, 395-402.

Hathaway, S.R., \& McKinley, J.C. (1951). The MMPI manual. New York: Psychological Corp.

Hawley, L., \& Butterfield, G. (1981). Exercise and the endogenous opiates. New England Journal of Medicine, 305, 1591 .

Hodgson, R.J., \& Rachman, S. (1977). Obsessionalcompulsive complaints. Behavior Research and Therapy, $15,389-395$.

Honnigman, J.J. (1967). Culture in personality. New York: Harper and Row.

Hoogduin, K. (1986). On the diagnosis of obsessivecompulsive disorder. American Journal of Psychotherapy, 40, 36-51.

Horney, K. (1950). Neurosis and human growth. New York: Norton.

Horney, K. (1945). Our inner conflicts. New York: Norton.

Horney, K. (1937). New ways in psychoanalysis. New York: Norton.

Ingram, D.H. (1982). Compulsive personality disorder. The American Journal of Psychoanalysis, $\underline{42}(3), 189-198$.

Insel, T.R. (1985). Obsessive-compulsive disorder. Psychiatric Clinics of North America, $8(1), 105-117$.

Insel, T.R. (1982). Obsessive-compulsive disorder--Five clinical questions and a suggested approach. Comprehensive Psychiatry, 23(3), 241-251.

Insel, T.R., Hoover, C., \& Murphy, D.L. (1983). The parents of patients with obsessive-compulsive disorder. Psychological Medicine, 13, 807-811.

Jablensky, A. (1985). Approaches to the diagnosis and classification of anxiety and related disorders. In Tuma, H. and Masters, J. (eds), Anxiety and Anxiety Disorders. Hillsdale, N.J.: Lawrence Erlbaum. 
Joseph, P., \& Robbins, J.M. (1981). Worker or runner? the impact of commitment to running and work on self identification. In Psychology of Running, (ed) M.H. Sacks and M.L. Sachs. Champaign, IL: Human Kinetics Publishers.

Kohut, H. (1971). The analysis of the self. New York: International Universities Press.

Kohut, H. (1977). The restoration of the self. New York: International Universities Press.

Kostrubala, T. (1976). The joy of running. Philadelphia: J.B. Lippincott.

Kringlen, E. (1965). Obsessional neurotics: A long term follow-up. British Journal of Psychiatry, 111, 709722 .

Lewis, A. (1936). Problem of obsessional illness. Proceedings of the Royal Society of Medicine, 29, 325326 .

Lo, W. (1967). A follow-up study of obsessional neurotics in Hong Kong Chinese. British Journal of Psychiatry, 113, 823-832.

Machlowitz, M.M. (1980). Workaholics. Reading, MA: Addison-Wesley.

Mahoney, M.J., \& Arnkoff, D.B. (1979). Self management. In O.F. Pomerleau and J.P. Brady (Eds.), Behavioral Medicine: Theory and Practice. Baltimore: Williams and Williams.

Masters, K.S., \& Lambert, M.J. (1989). On gender comparison and construct validity: An examination of the commitment to running scale in a sample of marathon runners. Journal of Sport and Exercise Psychology, $\underline{12}(2), 196-202$.

McFall, N.E., \& Wolldersheim, J.P. (1979). ObsessiveCompulsive neurosis: A cognitive behavioral

formulation and approach to treatment. Cognitive Therapy and Research, $3,333-348$.

Meichenbaum, D. (1974). Cognitive behavior modification. Morristown, NJ: General Learning Press.

Morgan, W.P. (1979). Negative addiction in runners. Physician and Sports Medicine, $Z(2), 56-63$. 
Morgan, W.P., \& Costill, D.L. (1972). Psychological characteristics of the marathon runner. Journal of Sports Medicine and Physical Fitness, 12, 42-46.

Morgan, W.P., \& Pollock, M.L. (1978). Psychological characteristics of the elite distance runner. In Milvy, P. (Ed.) The Long Distance Runner: A Definitive Study. New York: Urizen Books.

Naughton, T.J. (1987). A conceptual view of workaholism and implications for career counseling and research. The Career Development Quarterly. March, 180-187.

Nieman, D.C., \& George, D.M. (1987). Personality traits that correlate with success in distance running. Journal of Sports Medicine, 27, 345-355.

Nemiah, J. (1975). Obsessive-compulsive neurosis. In Freedman, A.M., Kaplan, H.T., Sadock, B.J. (Eds.), Comprehensive Textbook of Psychiatry. Baltimore: William Wilkins and Co.

Pargman, D., \& Baker, M.C. (1980). Running high: Enkephalin indicated. Journal of Drug Issues, 10, 341351 .

Paykel, E.S., \& Prusoff, B.A. (1973). Relationships between personality dimensions: Neuroticism and extraversion against obsessive, hysterical, and oral personality. British Journal of Social and Clinical Psychology, 12, 309-318.

Pacht, A.R. (1984). Reflections on perfection. American Psychologist, 39, 386-390.

Peele, S. (1981). How much is too much: Healthy habits or destructive addictions. Englewood Cliffs, NJ: Prentice-Hall.

Peele, S. (1985). The meaning of addiction: Compulsive experience and interpretation. Lexington, MA: Lexington Books.

Philpott, R. (1975). Recent advances in the behavioral measurement of obsessional illness difficulties common to these and other measures. Scottish Medical Journal, 20, 33-40.

Pollak, J.M. (1979). Obsessive-compulsive personality: A review. Psychological Bulletin, 86, 225-241. 
Price, M. (1980). Workaholism: Fears a job can't solve. Industry Week, 3 , 56-62.

Rachman, S. (1976). Some similarities and differences between obsessional ruminations and morbid preoccupations. Canadian Psychiatric Association Journal, $18,71-74$.

Rachman, S. (1976). The modification of obsessions: A new formulation. Behavior Research and Therapy, 14, 437443 .

Rachman, S., \& Desilva, P. (1978). Abnormal and normal obsessions. Behavior Research and Therapy, 16, 233248 .

Reich, W. (1949). Character analysis. New York: Farrar, Straus, and Giroux, p. 194.

Rinieris, P., Stefanis, C., and Rabavilas, A. (1981). Relationships between obsessional personality traits neuroticism and extraversion in normal subjects. Competitive Psychiatry, 22(5), 488-489.

Robbins, J.M., \& Joseph, P. (1980). Commitment to running: Implications for family and work. Sociological Symposium, 30, 87-108.

Rosenberg, C.M. (1967). Personality and obsessional neurosis. British Journal of Psychiatry, 113, 471477 .

Rudder, M., Gilmore, M., and Francis, A. (1982). Delusions when to confront the facts of life. American Journal of Psychiatry, 139, 233-248.

Sachs, M.L. (1981). Running addiction. In M.H. Sacks and M.L. Sachs (eds.), Psychology of running. Champaign, IL: Human Kinetics Publishers.

Sacks, M.H., \& Sachs, M.L. (1981). Psychology of running. Champaign, IL: Human Kinetics Publishers.

Salkovskis, P.M. (1985). Obsessiona1-compulsive problems: A cognitive-behavioral analysis. Behavior, Research and Therapy, 23(5), 571-583.

Salzman, L., \& Thaler, F.H. (1981). Obsessive-compulsive disorders--a review of the literature. American Journal of Psychiatry, 138, 286-296. 
Sandler, J., \& Rosenblatt, B. (1962). The concept of the representational world. Psychoanalytic study of the Child, 17, 128-145.

Schwartz, H.S. (1982). Job involvement as obsessioncompulsive. Academy of Management Review, 2, 429-432.

Schwartz, M.F., \& Brasted, W.S. (1985). Sexual addiction. Medical Aspects of Human Sexuality, 19, 103-107.

Sorozotkin, B. (1985). The quest for perfection: Avoiding guilt or avoiding shame? Psychotherapy, 22(3), 564571 .

Stein, L., \& Belluzzi, J.D. (1978). Brain-endorphines and sense of well being: A psychobiological hypothesis. In E. Costa \& M. Trabucchi (Eds.), Advances in Biochemical Psychopharmacology. New York: Raven Press.

Stewart, P. (1990). Guide to prize money, races and elite athletes. Arlington, VA: Road Race Management, Inc.

Stolorow, R., \& Lachmann, F. (1980). Psychoanalysis of developmental arrest: Theory and treatment. New York: International Universities Press.

Thaxton, L. (1982). Physiological and psychological effects of short term exercise addiction on habitual runners. Journal of Sport Psychology, 4, 73-80.

Thoren, P., Asberg, M., \& Cronholm, B. (1980). Clomipramine treatment of obsessive-compulsive disorder: A controlled clinical trial. Archives of General Psychiatry, 37, 1281-1289.

Waters, B. (1981). Defining the runner's personality. Runner's World, 16(6), 48-51.

Wedin, R.W. (1984). The sexual compulsion movement. Christopher Street, 8, 48-53.

Weisinger, H., \& Lorenz, N. (1981). Nobody's perfect. New York: Warner Books.

Weisz, D., \& Thompson, R. (1983). Endogenous opiods: Brain-behavior relations. In P. Levinson, D. Gerstein, D. Maloff, (Eds.), Commonalities in Substance Abuse and Habitual Behavior. Lexington, ME: Lexington Press. 
Worick, W.W., \& Schaller, W.E. (1977). Alcohol, tobacco and drugs: Their use and abuse. Englewood Cliffs, NJ: Prentice-Hall. 
APPENDIX A

OBSESSIVE-COMPULSIVE SCALE 
The Obsessive-Compulsive Scale

\section{True-False}

1. I feel compelled to do things I don't want to do.

2. I usually check things that I know I have already done.

3. I can walk 30 miles an hour.

4. I often do things I don't want to do because I can not resist doing them.

5. I seldom keep a daily routine.

6. I feel compelled to always complete what I am doing.

7. I often feel the need to double check what I do.

8. I'd rather do things the same way all the time.

9. I seldom have recurring thoughts.

10. I seldom am compelled to do something I don't want to do.

11. I don't feel uncomfortable and uneasy when I don't do things my usual way.

12. If I don't feel like doing something it doesn't bother me not to do it.

13. I usually never feel the need to be organized.

14. I am uneasy about keeping a rigid time schedule.

15. My birthday comes once a year.

16. I am often compelled to do some things I do not want to do.

17. I like to keep a rigid daily routine.

18. I believe there is a place for everything and everything in its place.

19. I seldom check things I know I have already done.

20. I am not obsessed with details.

21. I often have recurring thoughts.

22. I like to do things differently each time.

*Note. Items $1,2,4,6,7,8,16,17,18$, and 21 , are scored for compulsivity if answered true. Items $5,9,10,11,12,13,14,19,20$ and 22 , are scored for compulsivity if answered false. Items 3 and 15 are validity check items. 
161

APPENDIX B

NEGATIVE ADDICTION SCALE 
Negative Addiction Scale

1. During an average week I run
A) everyday
E) it varies
B) 6 days
C) 5 days
D) 4 days

2. On days that I don't run I usually feel
A) tense
B) guilty
D)

3. Since I have been running my interest and enjoyment in social activities has
A) increased
B) decreased
C) stayed the same

4. On days that I don't run I feel depressed or mentally sluggish.

5. On days that I don't run I feel deprived.

6. If I stopped running my physical health would decline significantly.

7. Running is my primary form of recreation.

8. I experience "runners high" on the majority of my runs.

9. Running is a common topic of conversation for me.

10. It is important for all runners to take some time off from their regularly held running routine.

11. Running has influenced my lifestyle.

12. My interest in running has caused some family or interpersonal tensions.

13. Check all of the responses that apply to your running behavior.

A) I run at approximately the same time every day.

B) I run in unfavorable environments (e.g., rain, cold, heat).

C) I have a consistent weekly running schedule with the same pattern of running and nonrunning days.

D) I run whatever time of the day is most convenient to my other daily activities. 
E) I have a training partner that I run with whenever possible.

F) I keep a written record of my running.

G) I plan my other daily activities around what time I want to run.

H) I am usually disciplined and do run on days that I really don't feel like doing it.

I) I set weekly mileage goals for myself.

J) I am able to meet the weekly mileage goals that I set.

K) I feel that if I do not maintain my self discipline, I would stop running completely tomorrow.

The scale has 14 possible points. One point was given for answer $1 \mathrm{~A} ; 2 \mathrm{~A}$ or $\mathrm{B} ;$ and $3 \mathrm{~B}$. Questions $4-12$ provided a semantic differential ranging from 1 (strongly agree) to 5 (strongly disagree). One point was given for all "strongly agree" responses to question four thru nine and questions 11 and 12 . One point was given for a response to "strongly disagree" to question 10. For question 13 one point was given for responses $B$ and 11 . 
APPENDIX C

COMMITMENT TO RUNNING SCALE 
Commitment to Running scale*

Feelings About Running**

The following statements may or may not describe your feelings about running. Read each statement and then circle the appropriate number to indicate how well the statement describes your feelings most of the time. There are no right or wrong answers. Do not spend too much time on any one item, but give the answers which seem to describe how you generally feel about running.

1. I look forward to running.

$$
\begin{aligned}
& \text { strongly } \\
& \text { disagree }
\end{aligned}
$$
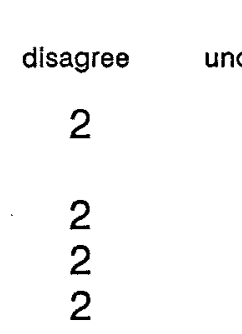

2. I wish there were a more enjoyable way to stay fit.

3. Running is drudgery.

4. I do not enjoy running.

5. Running is vitally important to me.

$\begin{array}{ll}1 & 2 \\ 1 & 2 \\ 1 & 2 \\ 1 & 2 \\ 1 & 2\end{array}$

6. Life is so much richer as a result of running.

7. Running is pleasant.

8. I dread the thought of running.

9. I would arrange or change my schedule to meet the need to run.

10. I have to force myself to run.

11. To miss a day's run is sheer relief.

12. Running is the high point of my day.

2

3

agree

strongly

4

5

3

3

3

4

5

5

4

5

1

2

3

4

5

3

$4 \quad 5$

$3 \quad 4 \quad 5$

1

3

4

5

12

3

4

5

12

3

4

5

12

3

4

5

1

2

3

4

5

*Items 2, 3, 4, 8, 10, 11 are scored in reverse.

**This title was used on the questionnaire to minimize possible response bias. 
APPENDIX D

RUNNING BEHAVIOR QUESTIONNAIRE 
Running Behavior Questionnaire

\section{PART A}

The following items are designed to assess running behaviors and thoughts about running. Please respond to each item. Respond how you feel most of the time. Remember there are no right or wrong answers.

1. During an average week I run
A) everyday B) 6 days
C) 5 days
D) 4 days
E) it varies

2. On days that I don't run I usually feel
A) tense
B) guilty
C) no different from running days

3. Since I have been running my interest and enjoyment in social activities has
A) increased
B) decreased
C) stayed the same

4. On days I don't run I feel depressed or mentally sluggish

5. On days I don't run I feel deprived

1

2

3

4

5

6. If I stopped running my physical health would decline significantly

1

2

3

4

5

7. Running is my primary form of recreation

2

3

4

5

8. I experience "runners high"

on the majority of my runs

2

3

4

5

9. Running is a common topic of conversation for me

10. It is important for all runners to take time off from their regularly held running routine 
11. Running has influenced my lifestyle 1

2

3

4

5

12. My interest in running has caused some family and inter-personal tension 1 2 3 4 5

13. Check all of the responses that apply to your behavior

A) I run at approximately the same time every day.

B) I run in unfavorable environments (e.g., rain, extreme cold, heat).

C) I have a consistent weekly running schedule with the same pattern of running and nonrunning days.

D) I run whatever time of the day is most convenient to my other daily activities.

E) I have a training partner that I run with whenever possible.

F) I keep a written record of my running.

G) I plan my other daily activities around what time I want to run.

H) I am usually disciplined and do run on days that I really don't feel like doing it.

I) I set weekly mileage goals for myself.

J) I am able to meet the weekly mileage goals that I set.

K) I feel that if I do not maintain my self discipline, I would stop running completely tomorrow.

\section{PART B}

The following statements may or may not describe your feelings about running. Read each statement and then circle the appropriate number to indicate how well the statement describes your feelings most of the time. There are no right or wrong answers. Do not spend too much time on any one item, but give the answers which seem to describe how you generally feel about running. 
1. I look forward to running.

2. I wish there were a more enjoyable way to stay fit.

3. Running is drudgery.

4. I do not enjoy running.

5. Running is vitally important to me.

strongly
disagree

disagree

uncertain

6. Life is so much richer as a result of running.

7. Running is pleasant.

8. I dread the thought of running.

\section{3}

5

1

2

3

3

5

9. I would arrange or change

$\begin{array}{lllll}1 & 2 & 3 & 4 & 5 \\ 1 & 2 & 3 & 4 & 5\end{array}$

my schedule to meet the need to run.

10. I have to force myself to run.

11. To miss a day's run is sheer relief.

12. Running is the high point of my day.

12

3

4

5

$\begin{array}{lllll}1 & 2 & 3 & 4 & 5\end{array}$

1

1

1
2

2

2
3

3

3
4

4

4
5

\section{PART C}

Please respond to the following item as you feel or act most of the time.

\section{True-False}

1. I feel compelled to do things I don't want to do.

2. I usually check things that I know I have already done.

3. I can walk 30 miles an hour.

4. I often do things I don't want to do because I can not resist doing them.

5. I seldom keep a daily routine.

6. I feel compelled to always complete what I am doing.

7. I often feel the need to double check what I do.

8. l'd rather do things the same way all the time.

9. I seldom have recurring thoughts.

10. I seldom am compelled to do something I don't want to do.

11. I don't feel uncomfortable and uneasy when I don't do things my usual way.

12. If I don't feel like doing something it don't bother me not to do it. 
13. I usually never feel the need to be organized.

14. I am uneasy about keeping a rigid time schedule.

15. My birthday comes once a year.

16. I am often compelled to do some things I do not want to do.

17. I like to keep a rigid daily routine.

18. I believe there is a place for everything and everything in its place.

19. I seldom check things I know I have already done.

20. I am not obsessed with details.

21. I often have recurring thoughts.

22. I like to do things differently each time.

\section{PART D}

In the following section please provide the appropriate information in the blanks where asked. Please circle the appropriate response to indicate how you feel most of the time in terms of your running behaviors on the appropriate items. There are no right or wrong answers.

1. On the average, how many miles per week do you train?

2. On the average how many hours per week do you run?

3. What is your age?

4. What is your sex? 1 (male) 2 (female)

5. What is your personal best time at

A) $10 \mathrm{~K}$

B) Marathon

6. On the average how many times per week do you do track work, factlek or some other type of "quality" workout?

7. At what level do you perceive yourself as being addicted to running?

$\begin{array}{lllll}5 & 4 & 3 & 2 & 1 \\ \text { very } & & & & \text { not at all }\end{array}$

addicted

8. How committed are you to reaching your full potential as a competitive runner?

$\begin{array}{lllll}5 & 4 & 3 & 2 & \begin{array}{l}1 \\ \text { not at all } \\ \text { cory } \\ \text { committed }\end{array} \\ \end{array}$


9. What level of personal satisfaction do you receive from your running? $\begin{array}{lllll}5 & 4 & 3 & 2 & 1\end{array}$ very satisfied not at all satisfied

10. How close do you feel you are running to your potential?

$\begin{array}{llll}5 \quad 4 & 3 & 2 & 1 \\ \text { at my } & & & \text { no where near } \\ \text { potential } & & & \text { my potential }\end{array}$

11. How many days did you miss running in the last year due to injuries?

12. How many days did you miss running in the last year due to illness?

13. How many times in the last year did you not do a planned "quality" workout due to illness or injury?

14. How many races which you planned to run in the past year were missed due to illness or injury?

15. How many years have you run competitively?

16. In your career how many times have you been injured which required you to take more than one week off from running?

17. Approximately how many days do you not run each year just for rest?

18. By whom are you coached?

$$
1 \text { (self) } 2 \text { (other person) }
$$

19. How confident are you in your training program?

$\begin{array}{lllll}5 & 4 & 3 & 2 & 1 \\ \text { very } & & & \begin{array}{l}\text { not at all } \\ \text { confident }\end{array} \\ \text { confident } & & & =\end{array}$

20. How much stress does running add to your life?

$\begin{array}{lllll}5 & 4 & 3 & 2 & 1 \\ \text { Extreme } & & & \begin{array}{l}\text { No stress } \\ \text { at all }\end{array}\end{array}$


21. How much stress does running reduce in your life?

$\begin{array}{lllll}5 & 4 & 3 & 2 & 1 \\ \text { Greatly } & & & \begin{array}{l}\text { No stress } \\ \text { reduction }\end{array} \\ \text { reduces } & & & \end{array}$

stress

22. How important do you feel that the willingness to endure pain and suffering is to achieving your potential as a runner?

$\begin{array}{lllll}5 & 4 & 3 & 2 & 1 \\ \begin{array}{l}\text { Very } \\ \text { important }\end{array} & & & \begin{array}{l}\text { Not at all } \\ \text { important }\end{array}\end{array}$

23. How good are you at dealing with pain and suffering?

$\begin{array}{lllll}5 & 4 & 3 & 2 & 1 \\ \text { Very } & & & & \begin{array}{l}\text { Not } \\ \text { good }\end{array} \\ \text { good } & & & & \end{array}$

24. How often do you practice imagery, visualization, or some type of mental training?
a) never
d) 3 to 6 times a week
b) once a week
e) 7 times a week
c) twice a week
f) more than 7 times a week 
APPENDIX E

COVER LETTER 
Dear Elite Runner:

As part of my ongoing research in the area of running behavior here at the University of Virginia, I am conducting a study which examines the thinking and behavior patterns of elite runners such as yourself.

Being a competitive runner myself, as well as a coach, I am well aware how busy you must be now with training, work, and family responsibilities. However, I hope you can take a few minutes to assist me. Through the results of this study I hope to better understand the thought and behavior patters of runners so that in the future runners, coaches and others associated with running can better understand how to help runners achieve their best performance possible.

Please fill out the following questionnaire. It should only take about ten to fifteen minutes to complete. Do not put your name or social security number on the questionnaire. Please return the completed questionnaire by December 5, 1990 using the enclosed addressed stamped envelope.

Please be as open and honest as you can in answering the questions so that the results of this study will be meaningful. If you should find any question to be offensive in any manner you don't have to answer it. All information which you provide is strictly confidential. Since your questionnaire cannot be identified in any way and because it is very important that you return the completed questionnaire, I will be sending everyone a post card followup reminder.

Thank you very much for your help. Please be sure to answer every question. Should you have any questions feel free to contact me.

Sincerely,

Richard Ferguson

Department of Human Services

Health \& Physical Education

University of Virginia

Charlottesville, VA 22903

(804) 296-9687 
Fellow Etonic Athlete:

As part of my ongoing research in the area of running behavior here at the University of Virginia, I am conducting a study which examines the thinking and behavior patterns of elite runners such as yourself.

Being a competitive runner myself, as well as a coach, I am well aware how busy you must be now with training, work, and family responsibilities. However, I hope you can take a few minutes to assist me. Through the results of this study I hope to better understand the thought and behavior patters of runners so that in the future runners, coaches and others associated with running can better understand how to help runners achieve their best performance possible.

Please fill out the following questionnaire. It should only take about ten to fifteen minutes to complete. Do not put your name or social security number on the questionnaire. Please return the completed questionnaire by December 5, 1990 using the enclosed addressed stamped envelope.

Please be as open and honest as you can in answering the questions so that the results of this study will be meaningful. If you should find any question to be offensive in any manner you don't have to answer it. All information which you provide is strictly confidential. Since your questionnaire cannot be identified in any way and because it is very important that you return the completed questionnaire, I will be sending everyone a post card followup reminder.

Thank you very much for your help. Please be sure to answer every question. Should you have any questions feel free to contact me.

Sincerely,

Richard Ferguson

Department of Human Services

Health \& Physical Education

University of Virginia

Charlottesville, VA 22903

(804) 296-9687 
Dear Elite Runner:

As part of my ongoing research in the area of running behavior here at the University of Virginia, I am conducting a study which examines the thinking and behavior patterns of elite runners such as yourself.

Being a competitive runner myself, as well as a coach, I am well aware how busy you must be now with training, work, and family responsibilities. However, I hope you can take a few minutes to assist me. Through the results of this study I hope to better understand the thought and behavior patters of runners so that in the future runners, coaches and others associated with running can better understand how to help runners achieve their best performance possible.

Please fill out the following questionnaire. It should only take about ten to fifteen minutes to complete. Do not put your name or social security number on the questionnaire. Please return the completed questionnaire by December 5, 1990 using the enclosed addressed stamped envelope.

Please be as open and honest as you can in answering the questions so that the results of this study will be meaningful. If you should find any question to be offensive in any manner you don't have to answer it. All information which you provide is strictly confidential. Since your questionnaire cannot be identified in any way and because it is very important that you return the completed questionnaire, I will be sending everyone a post card followup reminder.

Thank you very much for your help. Please be sure to answer every question. Should you have any questions feel free to contact me.

Sincerely,

Richard Ferguson

Department of Human Services

Health \& Physical Education

University of Virginia

Charlottesville, VA 22903

(804) 296-9687 
APPENDIX F FOLLOW-UP NOTICE 
Dear Elite Runner,

In the past few weeks. I sent you a questionnaire about running behavior. Your return is very important to my research. If you have not returned your completed questionnaire please do so by December 1st. If you have already returned it, thank you very much.

Richard Ferguson

University of Virginia 